Linköping Studies in Science and Technology

Dissertation No. 1935

\title{
Self-Assembled and Selective-Area Growth of Group III-Nitride Semiconductor Nanorods by Magnetron Sputter Epitaxy
}

\author{
Elena Alexandra Serban
}

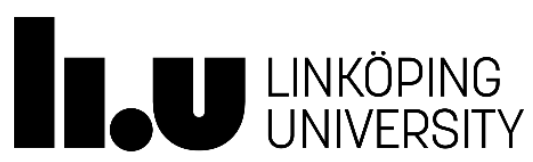

Thin Film Physics Division

Department of Physics, Chemistry and Biology (IFM)

Linköping University,

SE-58183 Linköping, Sweden

Linköping 2018 
The cover of this Thesis depicts a $45^{\circ}$ tilted-view scanning electron micrograph of a site-controlled array of GaN nanorods.

During the course of research underlying this Thesis, Elena Alexandra Serban was enrolled in Agora Materiae, a multidisciplinary doctoral program at Linköping University, Sweden.

(C) Elena Alexandra Șerban

ISSN 0345-7524

ISBN 978-91-7685-308-5

Printed in Sweden by LiU-Tryck, Linköping, 2018 


\section{Abstract}

The III-nitride semiconductor family includes gallium nitride $(\mathrm{GaN})$, aluminum nitride $(\mathrm{AlN})$, indium nitride $(\mathrm{InN})$, and the related ternary and quaternary alloys. The research interest on this group of materials is sparked by the direct bandgaps, and excellent physical and chemical properties. Moreover, the ternary alloys (InGaN, InAlN and AlGaN) present the advantage of bandgap tuning, giving access to the whole visible spectrum, from near infrared into deep ultraviolet wavelengths. The intrinsic properties of III-nitride materials can be combined with characteristic features of nanodimension and geometry in nanorod structures. Moreover, nanorods offer the advantage of avoiding problems arising from the lack of native substrates with film/substrate lattice and thermal expansion mismatch.

The growth and characterization of group III-nitride semiconductor nanorods, namely InAlN and GaN nanorods, is presented in this Thesis. All the nanostructures were grown by employing direct-current reactive magnetron sputter epitaxy. The results include the growth and study of both self-assembled and site-controlled grown nanorods.

$\mathrm{In}_{\mathrm{x}} \mathrm{Al}_{1_{-\mathrm{x}} \mathrm{N}}$ self-assembled, core-shell nanorods on $\mathrm{Si}(111)$ substrates were demonstrated. A comprehensive study of temperature effect upon the morphology and composition of the nanorods was realized. The radial nanorod heterostructure consists of In-rich cores surrounded by Al-rich shells with different thicknesses. The spontaneous formation of core-shell nanorods is suggested to originate from phase separation due to spinodal decomposition. As the growth temperature increases, In desorption is favored, resulting in thicker Al-rich shells and larger nanorod diameters. Moreover, the in-plane crystallographic relationship of the nanorods and substrate was modified from a fiber-textured to an epitaxial growth by removing the native $\mathrm{SiO}_{\mathrm{x}}$ layer from the substrate.

Self-assembled growth of GaN nanorods on cost-effective substrates offers a cheaper alternative and simplifies device processing. Successful growth of high-quality GaN (exhibiting strong bandedge emission and high crystalline quality) on conductive templates/substrates such as $\mathrm{Si}, \mathrm{SiC}$, $\mathrm{TiN} / \mathrm{Si}, \mathrm{ZrB}_{2} / \mathrm{Si}, \mathrm{ZrB}_{2} / \mathrm{SiC}, \mathrm{Mo}$, and $\mathrm{Ti}$ is supported by the possibility to be used as electrodes when integrated in optoelectronic devices. The influence of growth 
temperature upon the resulting size and optical properties of the nanorods was investigated. By applying a kinetic model, average diffusion length was calculated in correlation with growth temperature in order to explain the nanorods' morphology evolution.

The self-assembled growth leads to random nucleation, resulting in nanorods with large varieties of diameters, heights and densities within a single growth run. This translates into non-uniform properties and complicates device processing. These problems can be circumvented by employing selective-area growth. Pre-patterned substrates by nanosphere lithography resulted in $\mathrm{GaN}$ nanorods with controlled length, diameter, shape, and density. Well-faceted $c$ axis oriented $\mathrm{GaN}$ nanorods were grown directly onto the native $\mathrm{SiO}_{\mathrm{x}}$ layer inside opening areas exhibiting strong bandedge emission at room-temperature and single-mode lasing. The time-dependent growth series helped define a comprehensive growth mechanism from the initial thin wetting layer formed inside the openings, to the well-defined, uniform, hexagonal nanorods resulted from the coalescence of multiple initial nuclei.

Although nanosphere lithography is a fast and cheap patterning method, it does not offer the control on the size, position or density. The growth parameters were transferred onto focused ion beam lithography - patterned substrates which offers more control on the design. Focused ion beam lithography optimization included tailoring of the milling current (2-50 pA) and milling time $(5-50 \mathrm{~s})$. The patterning process optimisation enabled the minimization of mask and substrate damage, the key to attain uniform, welldefined, single, and straight nanorods. Destruction of the mask results in selective-area growth failure, while damage of the substrate surface promotes inclined nanorods grown into the openings, owning to random oriented nucleation. At lower growth temperatures $\left(950^{\circ} \mathrm{C}\right)$ nanostructures resulted from the coalescence of multiple, tilted, and irregular nanorods are observed. The tilting of the nanorods is reduced when increasing the growth temperature to $980{ }^{\circ} \mathrm{C}$ resulting in single and straight nanorods. The partial pressure of the $\mathrm{Ar} / \mathrm{N}_{2}$ working gas was also varied for achieving selectivity and single nanorods, and study the growth behaviour. By increasing the amount of Ar in the working gas from 0 to $50 \%$, we observe a transition of the target from a nitridized to metallic-state, affecting the sputtering conditions of the GaN nanorods. The change in the sputtering and deposition conditions influences the growth selectivity, coalescence, and growth rates. By balancing these effects, the selective growth of faceted, single nanorods was achieved. 


\section{Populärvetenskaplig sammanfattning}

En av de snabbast växande marknaderna just nu är halvledarindustrin, och prognoser indikerar en starkt utökad tillväxt de kommande åren. Optoelektronik är en dominerande del av den globala halvledarindustrin och introduceringen av den blå ljusdioden, med hög ljusstyrka, samt den blå-violetta laserdioden på 90-talet revolutionerade belysningsteknologin fram tills idag. Detta var startskottet för utvecklig av fasta tillståndets-dioder. Den förstnämnda består av ett aktivt lager av materialet InGaN och den senare är en kvantbrunnstruktur av multilager med InGaN.

Grupp III-nitrid-halvledare inkluderar galliumnitrid (GaN), aluminiumnitrid (AlN), indiumnitrid ( $\mathrm{InN})$ och relaterade legeringar, tillsammans möjliggör de ett direkt justerbart bandgap mellan $0.7 \mathrm{eV}(\operatorname{InN})-$ $3.4 \mathrm{eV}(\mathrm{GaN})-6.1 \mathrm{eV}(\mathrm{AlN})$. Bandgapskrökning, vilket är icke-linjära variationer av bandgapet orsakat av kompositionsförändringar, samt tryckegenskaper öppnar för nya applikationer för tre- och fyrkomponents legeringar.

Framkomsten av nanostrukturer av III-nitrid-halvledare genererade en betydande forskningsaktivitet där kombinationen av egenskaper som härrör från nanostavsgeometri och III-nitrid-halvledare-material utnyttjades. Tillräckligt små dimensioner på geometrierna bidrar till ändrade optiska, elektriska samt magnetiska egenskaper jämfört med bulkmaterialet (tredimensionella ursprunget). Utöver detta är innebär den reducerade dimensionen; utökad ytarea, hög densitet av elektroniktillstånd samt ökad ytspridning av elektroner och fononer. En-dimensionella nanostrukturmaterial såsom; nanostavar, nanotrådar samt nanokolumner har en utsträckning endast en dimension i storleksordningen 10-9 m. De erhöll extra uppmärksamhet på grund av att fabrikation av nanokomponenter och nano-sammanlänkningar blev realiserbara. Åtskilliga rapporter nyttjar nanostavar av III-nitrid-halvledare som byggstenar i nanokomponenter, speciellt inom optoelektronik där de är i framkant.

Den här avhandlingen redogör för tillväxt och karaktärisering av III-nitrid-nanostavar, specifikt InAIN och GaN, med nyttjandet av likströmsreaktiv-magnetronsputtring-epitaxi. Resultaten inkluderar tillväxt av både självsammansatta- och selektiv-yttillväxt av nanostavar. Även 
spontanformation av singelfas- och kärna-skal-nanostavar demonstreras. En omfattande undersökning av tillväxt-temperatur-effekter på morfologi, komposition samt på optiska egenskaper av nanostavar genomfördes. Kostnadseffektiva substrat som även förenklar komponentprocessening utforskades. En framgångsrik tillväxt av GaN-nanostavar realiserades på en rad olika substrat såsom; $\mathrm{Si}, \mathrm{SiC}, \mathrm{TiN} / \mathrm{Si}, \mathrm{ZrB}_{2} / \mathrm{Si}, \mathrm{ZrB}_{2} / \mathrm{SiC}, \mathrm{Mo}$, och Ti vilket påvisar teknikens mångfaldighet.

Den självsammansatta tillväxten leder till slumpartad nucleation, vilket resulterar i nanostavar med stor spridning på diameter, höjd samt densitet vid en enstaka tillväxtkörning. Detta påverkar egenskapernas uniformitet och därmed komponentprocessen. För att undvika detta användes selektiv yttillväxt at GaN-nanostavar på två olika substratbemönstringsmetoder: nanosfärisk- och fokuserad jonstrålningslitografi. GaN-nanostavar med kontrollerad längd, diameter samt form som innehar stark bandkantsemmission vid rumstemperatur och singlemod-lasring demonstrerades med hjälp av nanosfärisk litografi. En detaljerad tillväxtsmekanism definierades med hjälp av prov syntetiserade med varierade sputtringstider.

Nanosfärisk litografi är en snabb och billig bemönstringsteknik men den kan inte kontrollera storlek, position eller densitet. Tillväxtparametrar överfördes till fokuserad jonstrålning-litografi vilket resulterade $i$ en större kontroll över bemönstrings-designen. Optimering av både bemönstringsförhållanden (genom att skräddarsy förtunningstid, förtunningsström och bemönstringsdesign) och för tillväxtsförhållanden som temperatur och partialltryck resulterade i en uniform, väldefinierad, enstaka och raka nanostavar. 


\section{Preface}

The presented Thesis summarizes the knowledge and research results acquired during my PhD studies, from November 2013 until June 2018, in the Thin Film Physics Division, at the Department of Physics, Chemistry and Biology, Linköping University. Much of the foundation of this work is based on my Licentiate Thesis (Thesis no. 1788, 2017), entitled: "Magnetron Sputter Epitaxy of Group III-Nitride Semiconductor Nanorods”.

The aim and main achievement of the research was to develop new onedimensional group III-nitride semiconductor materials, namely GaN and InAlN, including self-assembled - single and core-shell nanorods, and site-controlled nanorod arrays by employing selective-area growth techniques like focused ion beam and nanosphere lithography.

This work was supported by the Swedish Research Council (VR) under grants Nos.621-2012-4420, 621-2013-5360, and 621-2016-04412. 


\section{Acknowledgement}

Firstly, I would like to express my sincere gratitude to my main supervisor Ching-Lien Hsiao, for sharing his knowledge and all the guidance offered during my studies. I was also lucky to have amazing co-supervisors: Jens Birch, Per Persson, and Lars Hultman and I'm grateful for their guidance, support, and encouragements in the past years.

I would also like to thank all the colleagues in Thin Film Physics Division for creating an inspiring working environment, and my co-authors: it has been a pleasure working with you.

Many of the "thank yous" go to my friends, from both Sweden and Romania, for helping me create great memories and making my days brighter (especially the 303-304, and Laura \& Iuliana - for going through this journey together).

Last but not least, I would like to send all the love and gratitude (which still wouldn't be enough) to my family and Pară: I wouldn't be what I am today without you! 


\section{Included papers and author's contribution}

\section{Paper I}

Structural and compositional evolutions of $\operatorname{In}_{\mathrm{x}} \mathrm{Al}_{1-\mathrm{x}} \mathrm{N}$ core-shell nanorods grown on $\mathrm{Si}(111)$ substrates by reactive magnetron sputter epitaxy

Elena Alexandra Serban, Per Ola Åke Persson, Iuliana Poenaru, Muhammad Junaid, Lars Hultman, Jens Birch, and Ching-Lien Hsiao

Nanotechnology 26, $215602 \quad-215610 \quad$ (2015), DOI: 10.1088/0957$4484 / 26 / 21 / 215602$

I was involved in conceiving the study and designed and performed the growth experiments. I performed the XRD, SEM, and statistical analysis of the results. I participated in the electron microscopy and pole figure characterization. I analyzed and interpreted the results, wrote the manuscript and revised it according to the co-authors feedback.

\section{Paper II}

Magnetron sputter epitaxy of high-quality GaN nanorods on functional and cost-effective templates/substrates

Elena Alexandra Serban, Justinas Palisaitis, Muhammad Junaid, Lina Tengdelius, Hans Högberg, Lars Hultman, Per Ola Åke Persson, Jens Birch, and Ching-Lien Hsiao

Energies 10(9), 1322 - 1334 (2017), DOI: 10.3390/en10091322

I was involved in conceiving the study and designed and performed most of the growth experiments (except $\mathrm{GaN}$ nanorods on metal and $\mathrm{SiC}$ templates/substrates). I performed the XRD, SEM, CL, and statistical analysis of the results. I participated in the electron microscopy and pole figure characterization. I analyzed and interpreted the results, wrote the manuscript and revised it according to the co-authors feedback. 


\section{Paper III}

Selective-area growth of single-crystal wurtzite GaN nanorods on $\mathrm{SiO}_{\mathrm{x}} / \mathrm{Si}(001)$ substrates by reactive magnetron sputter epitaxy exhibiting single-mode lasing

Elena Alexandra Serban, Justinas Palisaitis, Chia-Cheng Yeh, Hsu-Cheng Hsu, Yu-Lin Tsai, Hao-Chung Kuo, Muhammad Junaid, Lars Hultman, Per Ola Åke Persson, Jens Birch, and Ching-Lien Hsiao

Scientific Reports 7, 12701 (2017), DOI: 10.1038/s41598-017-12702-y

I was involved in conceiving the study and designed and performed the growth experiments. I performed the XRD, SEM, CL, and statistical analysis of the results and participated in the electron microscopy characterization. I analyzed and interpreted the results, wrote the manuscript and revised it according to the co-authors feedback.

\section{Paper IV}

Site-controlled growth of GaN nanorod arrays by magnetron sputter epitaxy

Elena Alexandra Serban, Justinas Palisaitis, Per Ola Åke Persson, Lars Hultman, Jens Birch, and Ching-Lien Hsiao

Thin Solid Films (2018) - In press, corrected proof, DOI: $10.1016 /$ j.tsf.2018.01.050

I conceived the study and designed and performed the growth experiments and substrate pre-patterning. I performed the XRD, SEM, and statistical analysis of the results and participated in the electron microscopy characterization. I analyzed and interpreted the results, wrote the manuscript and revised it according to the co-authors feedback. 


\section{Paper V}

Growth optimization of well-defined GaN nanorod arrays by reactive magnetron sputter epitaxy using an $\mathbf{A r} / \mathbf{N}_{2}$ gas mixture

Elena Alexandra Serban, Justinas Palisaitis, Per Ola Åke Persson, Lars Hultman, Jens Birch, and Ching-Lien Hsiao

\section{Manuscript in final preparation}

I conceived the study and designed and performed the growth experiments, substrate pre-patterning, and the structural characterization. I analyzed and interpreted the results and wrote the manuscript. 


\section{Related papers not included in the Thesis}

\section{Stacking fault related luminescence in GaN nanorods}

Mathias Forsberg, Elena Alexandra Serban, Iuliana Poenaru, Ching-Lien Hsiao, Muhammad Junaid, Jens Birch, and Galia Pozina

Nanotechnology 26, 355203 (2015), DOI: 10.1088/0957-4484/26/35/355203

2. Nucleation and core-shell formation mechanism of self-induced $\mathrm{In}_{\mathrm{x}} \mathrm{Al}_{1-\mathrm{x}} \mathrm{N}$ core-shell nanorods grown on sapphire substrates by magnetron sputter epitaxy

Ching-Lien Hsiao, Justinas Palisaitis, Per Ola Åke Persson, Muhammad Junaid, Elena Alexandra Serban, Per Sandström, Lars Hultman, and Jens Birch

Vacuum 131, 39 (2016), DOI: 10.1016/j.vacuum.2016.05.022

3. Polarization of stacking fault related luminescence in GaN nanorods

Galia Pozina, Mathias Forsberg, Elena Alexandra Serban, Ching-Lien Hsiao, Muhammad Junaid, Jens Birch, and Mikhail A. Kaliteevski

AIP Advances 7, 015303 (2017), DOI: 10.1063/1.4974461

4. Near band gap luminescence in hybrid organic-inorganic structures based on sputtered GaN nanorods

Mathias Forsberg, Elena Alexandra Serban, Ching-Lien Hsiao, Muhammad Junaid, Jens Birch, and Galia Pozina

Scientific Reports 7, 1170 (2017), DOI: 10.1038/s41598-017-01052-4 
5. Influence of InAIN Nanospiral Structures on the Behavior of Reflected Light Polarization

Yu-Hung Kuo, Roger Magnusson, Elena Alexandra Serban, Per Sandström, Lars Hultman, Kenneth Järrendahl, Jens Birch, and Ching-Lien Hsiao

Nanomaterials 8, 157 (2018), DOI: 10.3390/nano8030157 


\section{Table of Contents}

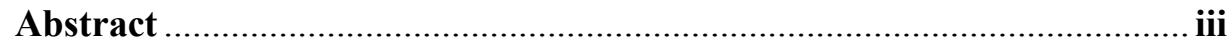

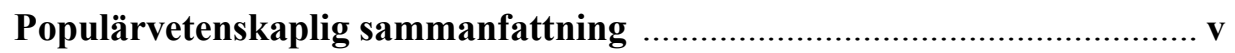

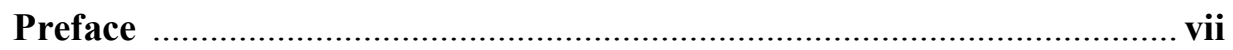

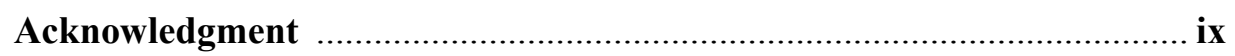

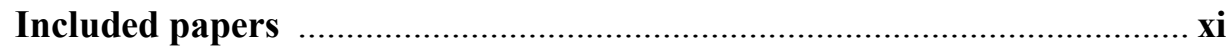

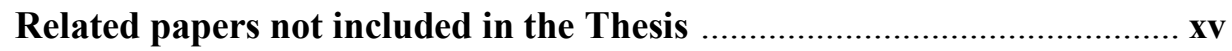

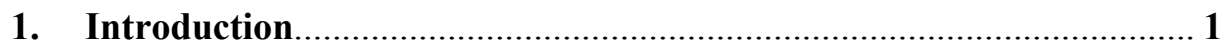

2. Group III-nitride semiconductors ................................................... 3

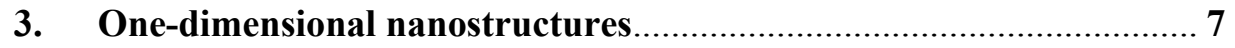

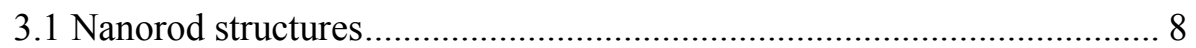

3.2 Synthesis of group III-nitride nanorods ............................................... 9

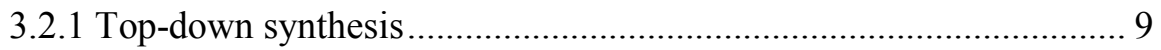

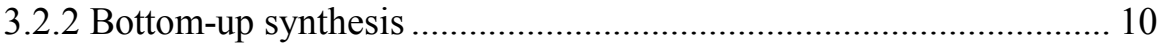

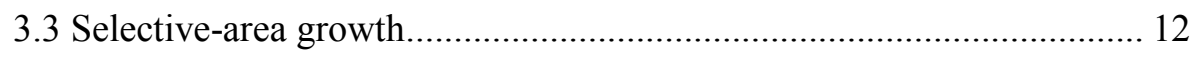

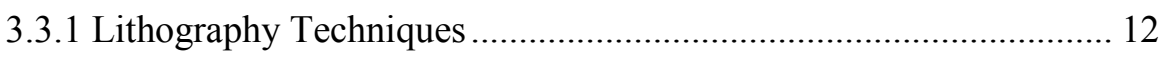

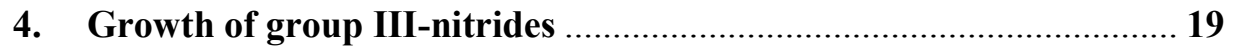

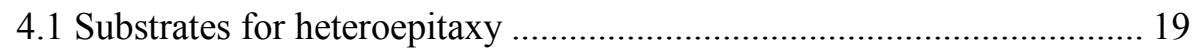

4.2 Metalorganic Chemical Vapor Deposition ......................................... 22

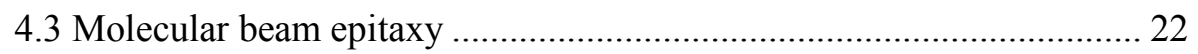

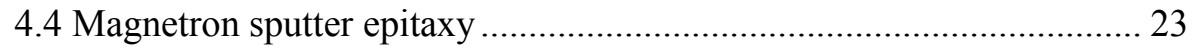

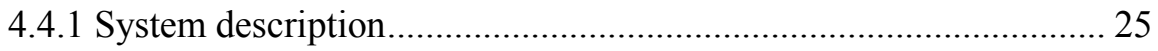

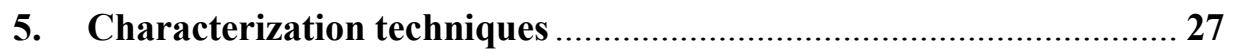

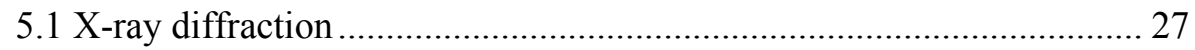

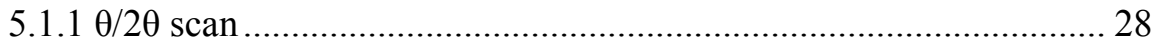

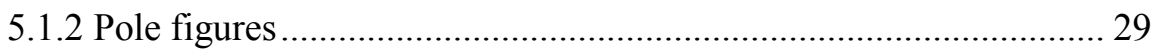

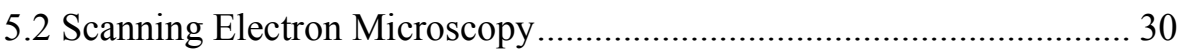

5.3 Cathodoluminescence spectroscopy ………….................................... 31

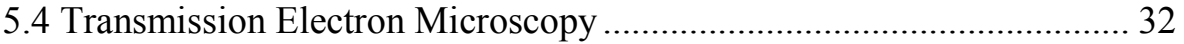

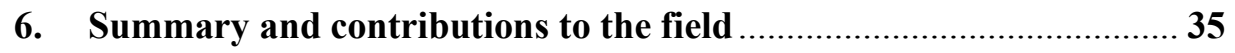

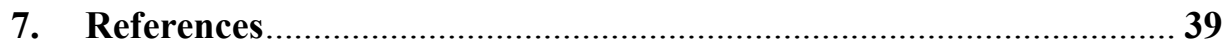

Papers 



\section{Introduction}

The semiconductor market is currently evaluated at approximately US\$ 400 billion, and prognosis supports a rapid expansion in the future. The optoelectronics segment currently dominates the global semiconductor industry as the fastest growing segment with around $10 \%$ of the total market share. [1] III-nitride semiconductors, gallium nitride $(\mathrm{GaN})$, aluminum nitride (AlN), indium nitride $(\mathrm{InN})$, and related alloys, present the advantage of direct tunable bandgaps $[0.7 \mathrm{eV}(\mathrm{InN})-3.4 \mathrm{eV}(\mathrm{GaN})-6.1 \mathrm{eV}(\mathrm{AlN})]$, and bandgap bowing (non-linear variation of the alloy bandgap with composition), imprinting properties that open up new applications for ternary and quaternary alloys. [2] In particular, the introduction of high-brightness blue light-emitting diodes (LEDs) with InGaN as the active layer, [3] and violet blue laser diode based on InGaN multiple-quantum-well structure [4] sandwiched in $p$-/ $n$-doped $\mathrm{GaN}$ epilayers in the 1990s, revolutionized and marked the rapid development of solid state lighting technology.

The first ones who investigated deeply the properties of this group of materials were Maruska and Pankove in the seventies. [5] However, these research programs were abandoned because of the inability to grow high-quality materials by heteroepitaxy and achieve $p$-type doping. The major breakthrough came in 1986 when Amano et al. succeeded growing high-quality GaN films on sapphire, using AlN buffer layers. [6] AlN layer was deposited at low temperature on sapphire before the growth of $\mathrm{GaN}$, to compensate the strain induced by GaN layer/sapphire substrate lattice mismatch. The same group reported low resistivity $p$-type in 1989, by using low-energy electron beam annealing to activate Mg-doped GaN. [7] However, good $p$-type group IIInitrides are still difficult to achieve. The difficulties arise from the ionization energies of acceptor dopants which are relatively high in III-nitrides, low dopant solubility, and hydrogen passivation. [8] This affects the performance of nitridebased devices for electronics, such as field-effect transistors, and also conducts to the so-called efficiency droop in LEDs (efficiency reduction at high current density injection). [9]

The emergence of group III-nitride semiconductors nanostructures saw intense research activity, combining the intrinsic properties of III-nitride 
materials with unique properties induced by the nanorod geometry. The distinctive features that nano-dimensionality offers like quantum confinement, high crystal quality, and strain relaxation promises significant advances in modern devices and especially for optoelectronics. [10] Group III-nitride nanorods were reported for the first time in 1998, obtained through selfassembly processes by molecular beam epitaxy (MBE). [11, 12]

Metal organic vapor phase epitaxy (MOCVD), MBE, and halide vapor phase epitaxy (HVPE) remain the main methods for synthesizing group III-nitride semiconductors. However, for the growth of high-quality materials, these techniques require a high growth temperature often limiting the composition range of the ternary or quaternary alloys to outside of the miscibility gap. Reactive magnetron sputter epitaxy (MSE) enables growth at lower temperatures and full composition range for single-phase $\operatorname{In}_{\mathrm{x}} \mathrm{Al}_{1-\mathrm{x}} \mathrm{N}$ alloys was achieved. [13] Moreover, MSE is a versatile, industrially-mature method, offering the possibility of large-scale production and expanding the applicability of these materials in the future.

The Thin Film Physics Division at Linköping University has for a long time been driving the development of MSE technique, being a pioneer among only a few active groups that use it successfully for the growth of group III-nitrides semiconductors. This knowledge, gained by years of researching sputtering processes in ultrahigh vacuum (UHV) systems conducted to the development of wurtzite III-nitrides semiconductors, which include thin films, [13-15] but also nanostructures like nanorods, [16, 17] nanospirals, [18] or nanograss. [19] 


\section{Group III-nitride semiconductors}

Group III-nitride semiconductors, including AlN, GaN, InN, and their alloys form a group of materials with high perspectives because of their good properties, such as: strong mechanical stability, high melting point, high thermal conductivity, chemical inertness, high breakdown voltages, and ability to sustain high-temperature and high-power operation. [2] Some important structural, electronic, thermal, and optical properties of wurtzite binary compounds are listed in Table 1.

Table 1. Properties of wurtzite binary group III-nitrides compounds. [20 - 22]

\begin{tabular}{|l|l|l|l|}
\hline & GaN & AlN & InN \\
\hline Bandgap energy $(\mathrm{eV})$ & 3.4 & 6.2 & 0.7 \\
\hline Lattice constant $(\AA)$ & $\begin{array}{l}\mathrm{a} 3.18 \\
{ }^{\mathrm{c}} 5.18\end{array}$ & $\begin{array}{l}\mathrm{a} 3.11 \\
{ }^{\mathrm{c}} 4.97\end{array}$ & $\begin{array}{l}\mathrm{a} 3.54 \\
\mathrm{c} 5.7\end{array}$ \\
\hline Effective electron mass $\left(\mathrm{m}_{0}\right)$ & 0.2 & 0.48 & 0.06 \\
\hline Electron mobility $\left(\mathrm{cm}^{2} \mathrm{~V}^{-1} \mathrm{~s}^{-1}\right)$ & $1000^{\text {(Th.) }}$ & $300^{\text {(Th.) }}$ & $14000^{\text {(Th.) }}$ \\
& $900^{\text {(Exp.) }}$ & $426^{\text {(Exp.) }}$ & $3980^{\text {(Exp.) }}$ \\
\hline Electron concentration $\left(\mathrm{cm}^{-3)}\right.$ & $\sim 10^{17}$ & $<10^{16}$ & $>10^{19}$ \\
\hline Dielectric constant $\left(\varepsilon_{0}\right)$ & 10 & $8.5 \pm 0.2$ & 15.3 \\
& & & \\
\hline Thermal conductivity $\left(\mathrm{Wcm}^{-1} \mathrm{~K}^{-1}\right)$ & 1.3 & 2 & 0.8 \\
\hline Thermal expansion coefficient & $\begin{array}{l}\mathrm{a} 5.59 \\
\left(\mathrm{x} 10^{-6} \mathrm{~K}^{-1}\right)(300 \mathrm{~K})\end{array}$ & ${ }^{\mathrm{c}} 4.2$ & $\mathrm{a} 5.7$ \\
\hline Melting point $\left({ }^{\circ} \mathrm{C}\right)$ & $>2500$ & ${ }^{\mathrm{c}} 5.3$ & $\mathrm{c} 3.7$ \\
\hline Bulk modulus $(\mathrm{GPa})(300 \mathrm{~K})$ & $210 \pm 10$ & 210 & $>11000$ \\
\hline Refractive index & 2.35 & 2.2 & 2.56 \\
\hline
\end{tabular}

They are direct bandgap materials and can crystallize in both wurtzite and zincblende polytypes (Figure 2.1). The difference between the polytypes consists in the stacking sequence: for the wurtzite phase ...ABAB... along the [0001] axis and ...ABCABC... along the [111] axis for the zincblende phase. 

A
(2)
Wurtzite unit cell

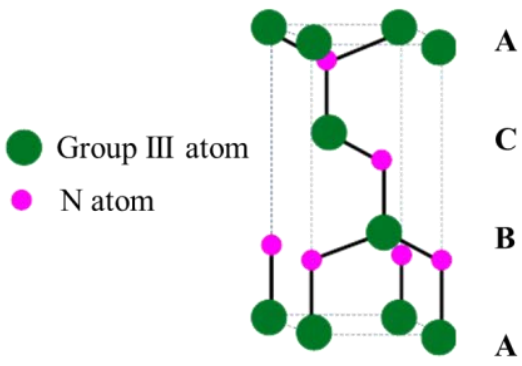
Zincblende unit cell

Figure 2.1. Wurtzite and zincblende unit cells for group III-nitride materials.

The atoms are tetrahedrally coordinated in both crystal structures. The Bravais lattice consists of two hexagonal close-packed sublattices shifted by $3 / 8$ [0001] for wurtzite, while for zincblende the structure consists of two face-centered cubic sublattices shifted in respect with each other by $1 / 4$ [111]. A sublattice consists of four atoms per unit cell where every group III atom is tetrahedrally coordinated by four atoms of nitrogen, and vice versa. For the growth of III-nitride semiconductors, it is important to mention that the wurtzite structure represents the thermodynamically stable phase. [23]

Properties and growth behaviors of these wurtzite materials are also strongly related to the polarity. The directions [0001] and [000-1] are not equivalent because of the lack of inversion symmetry as it can be seen in Figure 2.2. The wurtzite III-nitrides can have a metal ( $\mathrm{Ga}, \mathrm{Al}, \mathrm{In}$ )-face polarity if the group III atoms are facing towards the sample surface and vice versa for $\mathrm{N}$-face polarity.

The polarity of the grown structure can be influenced by the growth technique and conditions, but also by the substrate and buffer layer used during the growing process. It has been noticed that GaN films grown on sapphire by MOCVD [24] or HVPE [25] usually presents a Ga-face polarity, while, using MBE and a low-temperature AIN buffer layer, usually leads to N-face surfaces. [26] Besides the differences that appear in structure and morphology, the polarity also influences the electronic properties, samples with different polarities having different Schottky barrier heights. [27] 

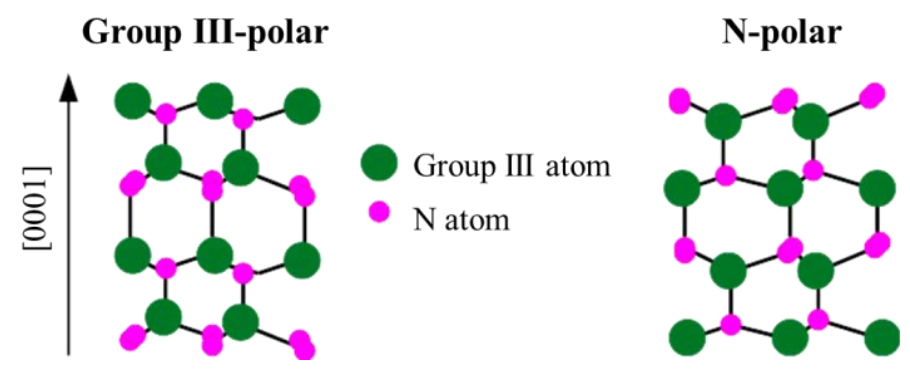

Figure 2.2. Group III- and N-polarity for wurtzite group III-nitride crystals.

Wurtzite ternary III-nitride alloys, $\operatorname{In}_{\mathrm{x}} \mathrm{Ga}_{1_{-\mathrm{x}} \mathrm{N}}, \mathrm{In}_{\mathrm{x}} \mathrm{Al}_{1_{-\mathrm{x}} \mathrm{N}}$, and $\mathrm{Al}_{\mathrm{x}} \mathrm{Ga}_{1-\mathrm{x}} \mathrm{N}$, are all direct bandgap semiconductors, and the bandgap spans from $\approx 0.7 \mathrm{eV}$ for InN, to $3.4 \mathrm{eV}$ for $\mathrm{GaN}$, and to $6.2 \mathrm{eV}$ for AlN. By tuning the bandgap of the ternaries, the whole visible spectrum can be covered from near IR into deep ultraviolet (UV) region. The bandgap energies exhibit bowing with composition, characterized by a bowing parameter, deviating from the linearity of Vegard's law according to Equation 2.1.

$$
E_{g}^{I n A l N}(x)=E_{g}^{A l N} \cdot x+E_{g}^{I n N} \cdot(1-x)-b \cdot x \cdot(1-x),
$$

where $\mathrm{E}_{\mathrm{g}}$ is the bandgap, $\mathrm{x}$ is the $\mathrm{Al}$ fraction, and $\mathrm{b}$ is the bowing parameter.

This deviation is presented in Figure 2.3, where the bandgap energy is plotted as a function of lattice constant considering the following bowing parameters: $1.6,0.7$, and 3.4 for $\operatorname{In}_{x} \mathrm{Ga}_{1_{-x}} \mathrm{~N}, \mathrm{Al}_{\mathrm{x}} \mathrm{Ga}_{1_{-\mathrm{x}} \mathrm{N}}$, and $\operatorname{In}_{\mathrm{x}} \mathrm{Al}_{1-\mathrm{x}} \mathrm{N}$, respectively. [21]

Of particular interest can be $\operatorname{In}_{x} \mathrm{Al}_{1-\mathrm{x}} \mathrm{N}$, due to the wide range of bandgap energies accessible, but also because it can be grown lattice-matched to $\mathrm{GaN}$ at a composition of $18 \% \mathrm{In}$, suitable for strain-free barrier and capping layer. Despites these perspectives, not many reports exist on the growth of $\mathrm{In}_{\mathrm{x}} \mathrm{Al}_{1-\mathrm{x}} \mathrm{N}$, a lot of problems arising from the high immiscibility in the range 0.1 $<\mathrm{x}<0.9$ and lattice mismatch between AlN and InN, of $\sim 13 \%$. These problems can be easily surpassed by using non-equilibrium growth techniques such as MSE, and full-composition range was demonstrated. [14, 17, 18] 


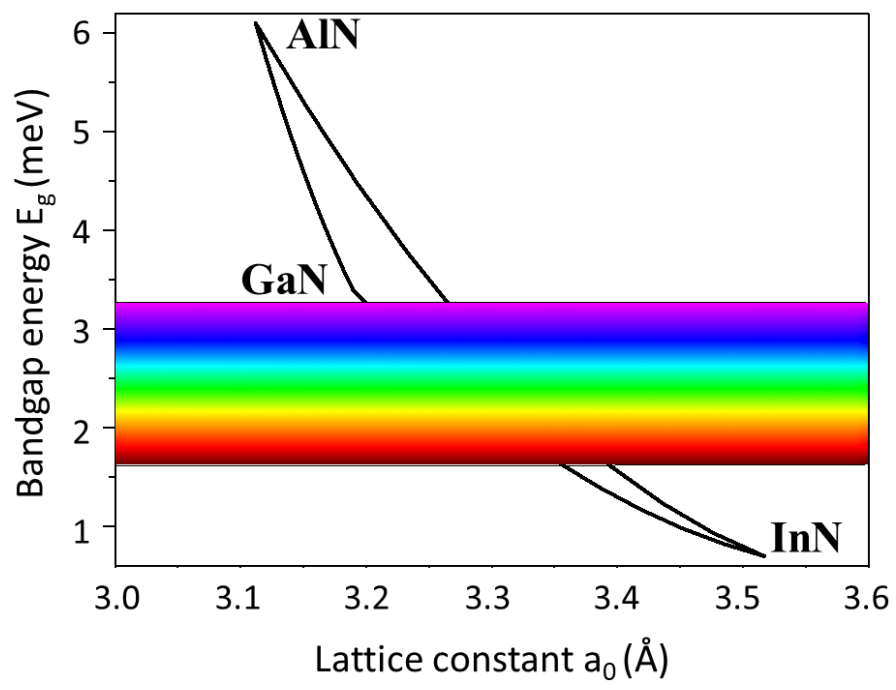

Figure 2.3. Bandgap energies as a function of lattice parameter of group IIInitrides. The values of the bowing parameters are: 1.6, 0.7 , and 3.4 for $\mathrm{In}_{\mathrm{x}} \mathrm{Ga}_{1_{-\mathrm{x}} \mathrm{N}}, \mathrm{Al}_{\mathrm{x}} \mathrm{Ga}_{1-\mathrm{x}} \mathrm{N}$, and $\operatorname{In}_{\mathrm{x}} \mathrm{Al}_{1_{-\mathrm{x}} \mathrm{N}} \mathrm{N}$, respectively. [21] 


\section{One-dimensional nanostructures}

One-dimensional (1D) nanostructured materials, such as nanorods, nanowires, or nanocolumns, which have one dimension of the order of $10^{-9} \mathrm{~m}$, gained attention because of their possible applications, being adequate for the fabrication of both nanoscale devices and interconnections owing to their size, morphology, and properties. [28, 10, 29]

Sufficiently small diameters result in different optical, electrical, and magnetic properties when compared to bulk, imprinted by the unique characteristics such as increased surface area, high density of electronic states, diameter-dependent bandgap, and increased surface scattering for electrons and phonons. If the size is close to the Bohr radius of the exciton (for $\mathrm{GaN}$ is within 2.8-11 nm), quantum confinement occurs resulting in a blue-shift of the excitonic transition energies. [30,31] At this scale, quantum confinement effects can be exploited in terms of tailoring geometry. For example, there is a dependence between size of the nanostructures and bandgap. Theoretical calculations show the bandgap increase with size decrease, implying that modifying the geometry and size offers the possibility of tuning the optical and electrical properties of nanostructured semiconductors. [32, 33]

Numerous works report the use of III-nitride semiconductor nanorods as building blocks in nanodevices, especially in optoelectronics where group III-nitrides are the front runners. Such devices include: nanolasers, [34] LEDs, [35] high electron mobility transistors (HEMTs), [36] nanosensors, [37] solar cells, [38] and nanogenerators. [39] These advances supported the intensive research dedicated to growth and development of III-nitride semiconductor nanorods in the past years. Various techniques were employed for the growth of 1D nanostructures, such as chemical vapor deposition, [40] laser ablation, [41] MOCVD, [42] MBE, [43] HVPE, [44] and MSE. [16, 17] 


\subsection{Nanorod structures}

Nanorods can be obtained as single phase or heterostructured nanorods (Figure 3.2). The heterostructures offer the possibilities of combining two or more materials, and so take advantage of the properties and characteristics of both. Owing to the small footprint, the structure degradation due to mismatch in lattice is avoided. Depending on the direction the materials are inserted, we can have radial nanorod heterostructure (termed as core-shell structure), or axial nanorod heterostructure.

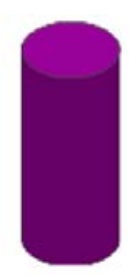

Single nanorod

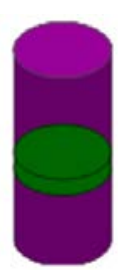

Nanorod axial heterostructure

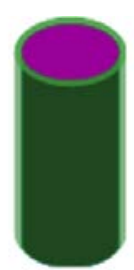

Nanorod radial heterostructure (core-shell nanorod)

Figure 3.2. Representation of single-phase and heterostructured nanorods from the geometrical combination of two materials.

Axial nanorod heterostructures simplify the production of devices such as LEDs, [45] and lead to improved size-dependent properties but also offer an easy way of incorporating quantum wells and dots in the active regions. $[46,47]$

Radial nanorod heterostructures consist of a nanorod core region surrounded by coaxial shell layers. [48] There are two ways of obtaining coreshell nanorods. One is a two-steps method consisting in growing a single nanorod (core), which is then coated with another material (shell), usually with a larger bandgap. [49] Another method consists of a single-step growth and refers to the spontaneous formation of core-shell nanorods consisting of two phases with different concentrations. [50,17] In a ternary III-nitride, a complete phase separation can occur, resulting in nanorods where the core and the shell are each composed of a binary compound. An incomplete phase separation results in compositional fluctuation, and both the shell and core of the nanorods are composed of ternary material, but with a different concentrations $\mathrm{x}$. 


\subsection{Synthesis of group III-nitride nanorods}

\subsubsection{Top-down synthesis}

Fabrication of nanorods can be approached by top-down or bottomup methods. Top-down methods offers the advantage of patterning with better reproducibility and dimension control accuracy. However, top-down fabrication includes several processing steps in order to reach to the final nanorod shape: epitaxy, patterning, and etching. A typical process of obtaining axial nanorod heterostructures by electron beam lithography is presented in Figure 3.3.

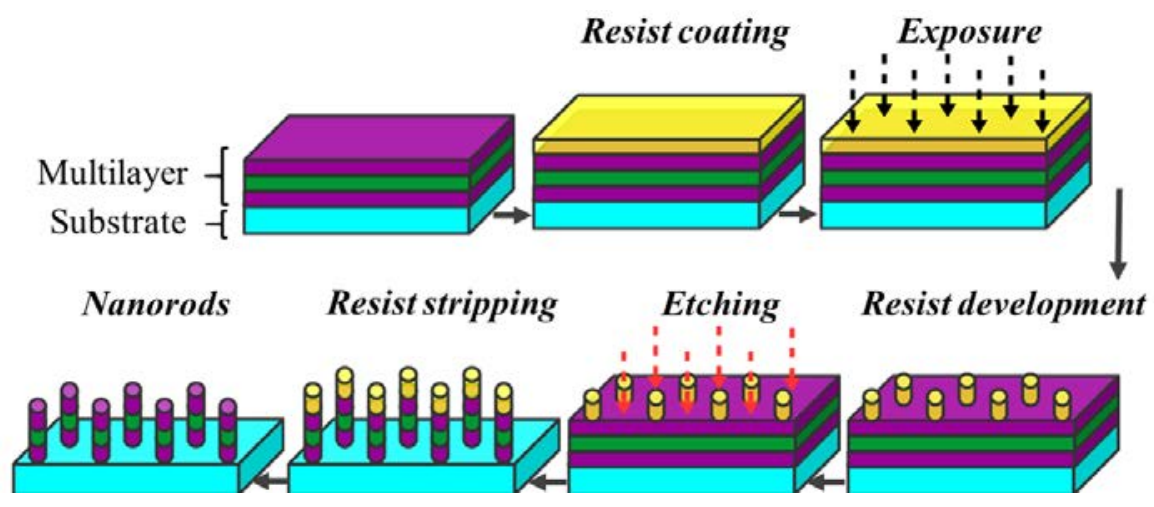

Figure 3.3. Typical processing steps for obtaining nanorods from thin films by a top-down method.

The starting point is a bulk material or a film which can be obtained by different epitaxy methods, and from which material is carved away until nanorods with the desired size are obtained. Heterostructured nanorods can be obtained from multilayers. Next, the patterning is applied by the use of a lithographic technique such as photolithography, electron beam lithography, nanoimprint lithography, focused on beam lithography or nanosphere lithography. The desired pattern is transferred with the help of a photo- or electro-sensitive polymer called resist or by coating the surface with a solution of dispersed nanospheres (nanosphere lithography). The uncovered areas are afterwards etched away by a dry or wet etching procedure. [51, 52] 


\subsubsection{Bottom-up synthesis}

Bottom-up methods require less effort and result in a better crystalline quality of nanorods and smoother side surfaces since no nanorod etching step is involved. [50] The growth process can be catalyst-assisted, also termed as vapor-liquid-solid (VLS) growth, or catalyst-free leading to the selfassembled nanorods.

\section{Catalyst-assisted growth}

The catalyst-assisted VLS growth process was first proposed by Wagner and Ellis in 1964, for the growth of Si whiskers, using gold catalyst. [53] The growth mechanism describes unidirectional growth resulted from the impinging of the vapor-phase precursor of the nanorod material on a liquidphase seed droplet (Figure 3.4).

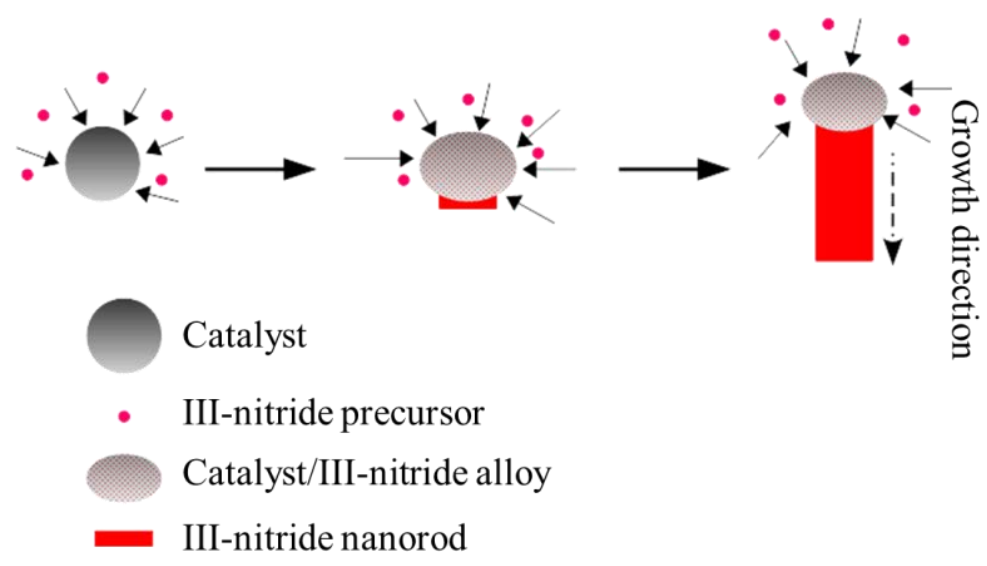

Figure 3.4. Catalyst-assisted growth of III-nitride nanorods.

The commonly used catalysts for $\mathrm{GaN}$ nanorod growth are $\mathrm{Au}, \mathrm{Ni}$, a mixture of both, or Ta. The catalyst is either coated on the substrate and thermally annealed to result in metallic droplets, or deposited as particles on the substrate's surface. Catalyst/III-nitride precursor alloying takes place, resulting in supersaturation of the liquid alloy and precipitation at the liquid/solid interface. The precipitation leads to nanorod growth, which continues as long as the vapor-phase reactants are supplied. 
Position-controlled growth can be applied by patterning of the catalyst, employing lithography methods. However, the crystal quality is often affected by the incorporation of the catalyst material into the nanorod. The presence of $\mathrm{Ni}$ catalyst was reported to affect the structural and optical properties of the $\mathrm{GaN}$ nanorods, being connected to stacking fault formation or stabilization of zincblende structure. [54]

\section{Catalyst-free growth}

Catalyst-free growth, also termed as self-assembled or self-induced growth, denotes the spontaneous formation of nanorods during growth. Spontaneous formation was proved using different methods such as MBE, MOVPE, HVPE, or MSE. Growth is not determined anymore by the catalyst presence, but surface diffusion and adatom mobility control more on the process and resultant morphology. [55]

Spontaneous III-nitride nanorod growth can be divided into two steps: nucleation and growth. Processes as adsorption, diffusion, and desorption are essential for understanding the nucleation and growth in this case. During the nucleation, adatoms migrate on the surface of the substrate and are adsorbed, leading to the formation of stable clusters. The coarsening of these clusters results in the nanorod's nuclei formation and kinetics determine the elongation and final nanorod growth. $[43,56]$ The general rule is that nanorods grow in the direction of minimizing the total surface energy of the crystal. [57] III-nitride nanorods usually grow preferentially along $c$-axis, since the average surface energies of the polar and semipolar planes are higher than those of nonpolar planes. [58] Adatoms tend to migrate along the substrate surface and the lateral nonpolar planes of nanorods, being incorporated primarily in the nanorod top polar planes. The diffusion-induced growth means that nucleation of nanorods is mainly random resulting in a large variety of diameters, heights, and densities within a single growth run. 


\subsection{Selective-area growth}

The randomness specific to self-assembled nanorods leads to nonuniform properties and hinders device processing. Selective-area growth (SAG) of nanorods was introduced to circumvent these problems, since it offers precise control on size (length and diameter), shape, position, density, and orientation of the nanorods. [59,60] SAG assumes a combination of top-down (lithographic patterning for template definition) and bottom-up (epitaxial growth of the nanorods on the template) methods resulting in highly-controlled nanorods. Prepatterned substrates, with mask layers that limit the growth to specific areas are employed for SAG of uniform nanorod arrays. The commonly used mask materials are: $\mathrm{TiN}_{\mathrm{x}}$, [61] $\mathrm{SiN}_{\mathrm{x}}$ [62] or $\mathrm{SiO}_{2}$. [63] After the deposition of the mask layer, lithographic methods are used to define the growth area such as: photolithography (PL), electron beam lithography (EBL), focused ion beam lithography (FIBL), laser interferometric lithography, nanoimprint lithography (NIL), or nanosphere lithography (NSL).

\subsubsection{Lithography Techniques}

SAG is a combination of top-down methods (used for creating the patterned substrate), with bottom-up epitaxy on the previously defined template, used for creating regular arrays of nanorods. These template-based methods are commonly used for creating a variety of nanostructures including zerodimensional (nanoparticles, quantum dots), one-dimensional (nanorods, nanowires, nanotubes) and two-dimensional (nanosheets) materials. However, the lithographic techniques are usually complicated, involving several processing steps, time-consuming, and expensive. We can roughly divide the lithographic techniques into two categories: radiation-based and non-radiationbased patterning. [64] Radiation-based patterning refers to lithographic techniques which employ various types of radiation such as: photons (PL), electrons (EBL), or ions (FIBL) to define the desired pattern. Non-radiationbased patterning methods are much cheaper and employ mechanical (transfer of the pattern by using a stamp - NIL) or/and chemical (self-assembly due to chemical energy - NSL) means for creating the template. 
Table 2. Specification of the most common lithography techniques used in group III-nitride growth. [65, 66]

\begin{tabular}{|l|l|l|l|l|}
\hline Technique & $\begin{array}{l}\text { Minimum } \\
\text { feature size }\end{array}$ & Throughput & Cost & Use \\
\hline Photolithography & $50-100 \mathrm{~nm}$ & Very high & Medium & $\begin{array}{l}\text { Industry, } \\
\text { R\&D }\end{array}$ \\
\hline $\begin{array}{l}\text { Electron beam } \\
\text { lithography }\end{array}$ & $5 \mathrm{~nm}$ & Very low & High & R\&D \\
\hline $\begin{array}{l}\text { Focused ion beam } \\
\text { lithography }\end{array}$ & $20 \mathrm{~nm}$ & $\begin{array}{l}\text { Medium- } \\
\text { low }\end{array}$ & Medium & R\&D \\
\hline $\begin{array}{l}\text { Nanoimprint } \\
\text { lithography }\end{array}$ & $40 \mathrm{~nm}$ & High & Low & $\begin{array}{l}\text { Industry, } \\
\text { R\&D }\end{array}$ \\
\hline $\begin{array}{l}\text { Nanosphere } \\
\text { lithography }\end{array}$ & $50 \mathrm{~nm}$ & High & Low & R\&D \\
\hline
\end{tabular}

The most common methods for nanopatterning are described below and their specifications are described in Table 2.

\section{Focused ion beam lithography (FIBL)}

FIBL is similar with EBL, only that instead of electrons an accelerated ion beam (typically gallium ion) is used, allowing the direct-writing on mask layers or substrates. FIBL also enables more capabilities including: local milling by sputtering atoms, pattern a resist layer, local deposition, local ion implantation. FIBL is more expensive and slower than PL or non-radiationbased methods, but still cheaper and faster that EBL. [67] After process optimization, nanorods with similar geometry and high precision ordering were proved using both methods (EBL and FIBL), and moreover FIBL showed to be more beneficial due to the elimination of the etching step which can increase roughness and substrate contamination. [68]

On the other side, patterning issues associated with FIBL include: surface roughening, differential milling, re-deposition of the sputtered material, ion incorporation or difficult pattern definition for smaller sizes due to the rounding of edges and inclined sidewalls induced by the Gaussian beam profile. [69]

The patterns to be exposed were designed using CleWin software (Figure 3.5a). The FIBL process was optimized by testing different patterning conditions for obtaining well-defined openings in the $\mathrm{TiN}_{\mathrm{x}}$ mask and minimize 
substrate damage. Patterning optimization included tailoring of the milling current (2-50 pA) and milling time (5-50 seconds). The highest milling current tested, of $50 \mathrm{pA}$ resulted in the complete destruction of the mask layer so that nanorods grew in a self-induced mode directly onto the Si substrate. A decrease of the milling current to $20 \mathrm{pA}$ induces less damage of the mask layer, so that the proximity effect is less pronounced, and portions of the mask remain unaffected. The pattern is still overexposed in these conditions and the openings are poorly defined with a diameter much larger that the design (Figure 3.5b). Growth results in multiple tilted nanorods and growth on the mask also occurs (Figure 3.5d). Low milling currents are necessary to avoid damaging the whole mask layer. A minimum ion beam-induced substrate damage and well-defined pattern is achieved at low currents of $2 \mathrm{pA}$ and short milling times of 5 seconds (Figure 3.5c). In these patterning conditions growth results in single, straight nanorods with uniform sizes, and only in the designated positions (Figure 3.5e).

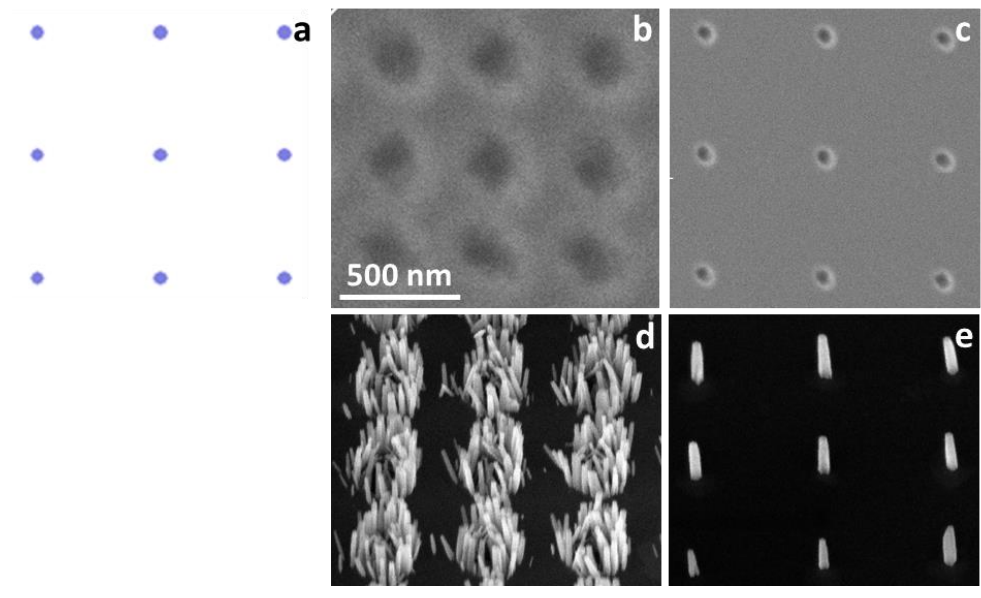

Figure 3.5. FIBL optimization by tailoring of the milling current. a) Pattern design using CleWin software, b) SEM image of the resulting pattern after exposed to $20 \mathrm{pA}$ for 5 seconds, c) SEM image of the resulting pattern after exposed to $2 \mathrm{pA}$ for 5 seconds, d) growth on pattern b), e) growth on pattern b). All images have the same scale.

Another step in FIBL optimization was tailoring of the milling time. Even for a very low milling current of $2 \mathrm{pA}$, the effect of the milling time is visible (Figure 3.6). 

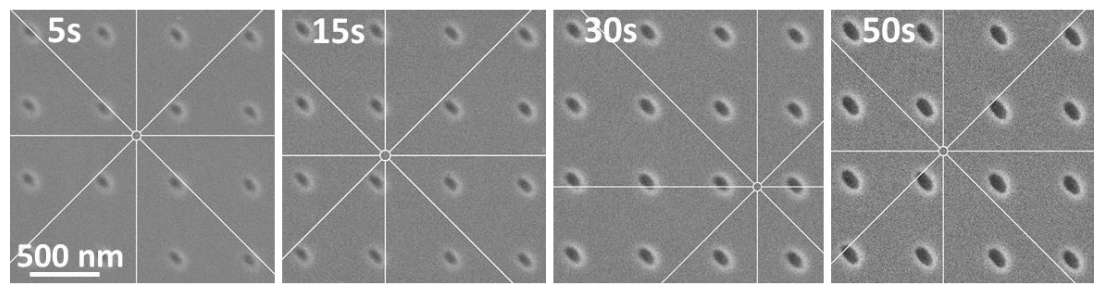

Figure 3.6. FIBL optimization by tailoring of the milling time. Tilt-view SEM images of the resulting patterns after exposed to $2 \mathrm{pA}$ for different milling times: 5, 15, 30, and 50 seconds. The crossed-lines represent the cross-mark used for alignment at different tilt angles. All images have the same scale.

Although the pattern is well-defined and mask remains undamaged, long milling times induce extensive substrate damage resulting in rough substrate surface which conducts to the growth of multiple, tilted nanorods inside one opening. The tilted growth, is determined both by the surface roughening of the substrate, but also by the inclined sidewalls induced by the Gaussian beam profile. Moreover, when increasing the milling from 5 to 50 seconds, the diameter of the opening also increases and material redeposition around the openings can be observed.

\section{Photolithography (PL)}

$\mathrm{PL}$, also known as optical lithography is a technique which uses light to transfer a designed pattern onto a substrate through a light-sensitive polymer called photoresist. The PL process combines several steps in sequence. After the cleaning, the substrate is covered with a thin layer of photoresist (usually through spin-coating). The photoresist is subjected to a designed pattern of intense light, which causes chemical changes in the polymer. In a positive photoresist, the chemical change induced by light is that the exposed areas become soluble in the developer which is used after to remove the exposed parts. In a negative photoresist, the illumination causes cross-linking of the polymer in the exposed areas so that the unexposed areas can be removed with the help of a developer. The pattern created in the photoresist is after that transferred to the substrate through an etching process. [70]

However, nanofabrication through PL is limited by the low resolution achievable, which is limited by the wavelength of light. Resolution 
enhancement methods include decreasing the wavelength of the source, optics improvement, and optimizing the chemistry of the photoresist. [71, 72]

\section{Electron beam lithography (EBL)}

The EBL process is similar with the PL process, but instead of light a focused beam of electrons is used to create the designed pattern in the resist. By selective removal, a pattern is created in the resist, which is after that transferred to the substrate. The use of electrons makes EBL a powerful tool which delivers highest resolution (sub-10 nm) and accuracy for nanopatterning, compared to other lithographic techniques. The method is however limited to research use or low-production industry, being a complex process with high cost, and very low throughput. [73, 74]

\section{Nanosphere lithography (NSL)}

NSL also known as colloidal lithography or natural lithography, uses self-assembled layers of spheres for pattern definition. There are two methods to produce the template for the subsequent nanorod growth. [65]

In a first approach (Figure 3.7a), the nanospheres are spread in a hexagonally close-packed way on the surface. A metal, which will play the role of the catalyst for VLS growth, is deposited on the top. The removal of the nanospheres leaves regular patterns of triangularly-shaped catalyst on the substrates surface, which define the position of the nanorods. [75]

In the second approach (Figure 3.7b) the nanospheres are spread in a spaced way on the substrate, or an etching step is applied on the close-packed nanospheres to reduce the size and increase the spacing. A mask layer is deposited and the nanospheres are chemically or mechanically removed. This process will result in openings in the mask layer and the nanorods will grow inside these openings. [76] 
Hexagonally close-packed nanospheres on a substrate

\section{Catalyst deposition Resulting pattern}
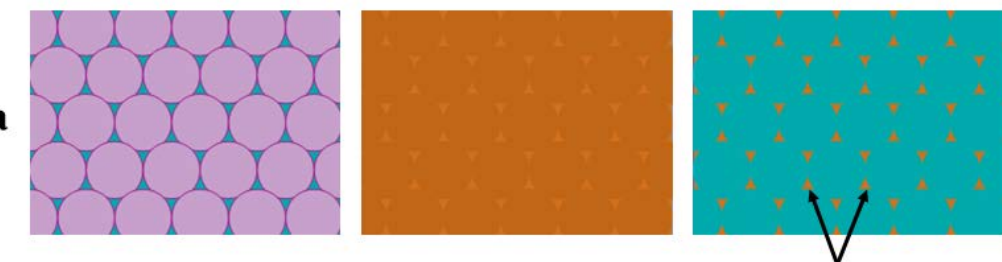

Nanorod positions (VLS growth)

Nanospheres spread on a substrate

Mask deposition

Resulting pattern after removal of the nanospheres
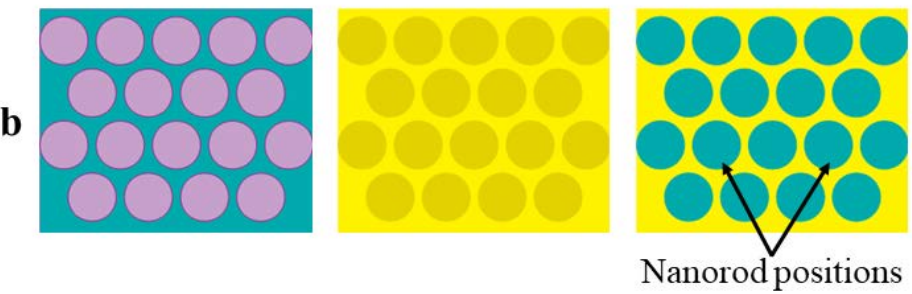

Figure 3.7. NSL approaches for nanorod growth resulting in arrays of a) triangularly-shaped metal catalyst for VLS growth and b) openings in a mask layer.

\section{Nanoimprint lithography (NIL)}

NIL is a non-radiation-based technique which creates patterns by mechanical deformation of an imprint resist with the help of a stamp. Typically, the stamp pattern is created with the help of other lithographic methods, such as FIBL and EBL. The pattern on the stamp is transferred by direct contact of the stamp with a thermoplastic or UV-resist. Key factors for a high transfer fidelity are represented by the quality of the stamp and imprint resist. The advantage of NIL is that it can create complex patterns on large areas, with low cost and high throughput. [77] Due to the mechanical imprint, special care has to be dedicated to the defects and mask damage that can result. [78, 79] 


\section{Growth of group III-nitrides}

\subsection{Substrates for heteroepitaxy}

Group III-nitrides can be grown both homoepitaxially and heteroepitaxially. Homoepitaxy means the substrate is the same material as the grown material, while in heteroepitaxy the substrate and grown material are different. Heteroepitaxy is commonly used for the growth of group III-nitride due to difficulties in achieving bulk group III-nitride substrates.

The lack of native substrates represents a major problem for the growth of III-nitride films, resulting in a high density of dislocations induced by the film - substrate mismatch. Dislocations act as non-radiative centers, decreasing luminescence efficiency, and leading to degradation of optoelectonic devices. [80] The nanorod geometry, with the characteristic small crosssections, allows them to accommodate much higher levels of strain induced by lattice mismatch. The crystal structure can elastically relax for a wider range of mismatches, and dislocations are either confined to the interface or are likely to bend to the sidewalls, enabling the growth of defect-free nanorods on a wide range of substrates. Besides, the small footprint of the nanorods contributes to avoidance of crack generation by relieving the strain induced by thermal expansion mismatch with the substrate.

The usage of native substrates would avoid the mismatch and buffer layer necessity problems, but they are expensive and not available in large sizes since none of the classical bulk growth methods was proven to be successful. A lot of problems can be associated with heteroepitaxy, the substrate having an important role in: crystal orientation, polarity, polarization, polytype, surface morphology, elastic strains, and concentration of defects. A series of factors, both technological and economical, must be taken into consideration when deciding the choice of substrate for heteroepitaxy, such as: lattice matching, thermal expansion coefficient, stability, thermal and electrical conductivity, availability, and price. Characteristics of the most commonly used substrates for III-nitride heteroepitaxy are presented in Table 3. 
Table 3. Characteristics of the most common substrates used for $\mathrm{GaN}$ growth. [81]

\begin{tabular}{|c|c|c|c|}
\hline & $\mathrm{Al}_{2} \mathrm{O}_{3}(0001)$ & $\mathrm{SiC}(6 \mathrm{H}, 4 \mathrm{H})$ & $\operatorname{Si(111)}$ \\
\hline Lattice mismatch (\%) & 13.8 & 3.1 & 17 \\
\hline $\begin{array}{l}\text { Thermal expansion } \\
\text { coefficient }\left(\alpha_{\mathrm{a}}, \mathrm{K}^{-1}\right)\end{array}$ & $7.5 \times 10^{-6}$ & $4.2 \times 10^{-6}$ & $2.6 \times 10^{-6}$ \\
\hline$\Delta \alpha_{\mathrm{a}},\left(\mathrm{K}^{-1}\right)$ & $-1.9 \times 10^{-6}$ & $1.4 \times 10^{-6}$ & $3 \times 10^{-6}$ \\
\hline $\begin{array}{l}\text { Electrical } \\
\text { characteristics }\end{array}$ & Insulator & $\begin{array}{l}\text { Semiconductor } \\
\text { Semi-insulator }\end{array}$ & Semiconductor \\
\hline Cost, availability & $\begin{array}{l}\text { Cheap, up to } \\
4 \text {," }\end{array}$ & $\begin{array}{l}\text { Expensive, up to } \\
6,\end{array}$ & Cheap, up to $18^{\prime}$ \\
\hline Problems & $\begin{array}{l}\text { Insulating, } \\
\text { lattice and } \\
\text { thermal } \\
\text { coefficient } \\
\text { mismatch, } \\
\text { low thermal } \\
\text { conductivity }\end{array}$ & $\begin{array}{l}\text { Expensive } \\
\text { (unsuitable for } \\
\text { mass- } \\
\text { production), } \\
\text { wetting } \\
\text { problems }\end{array}$ & $\begin{array}{l}\text { Lattice and } \\
\text { thermal } \\
\text { coefficient } \\
\text { mismatch, melt- } \\
\text { back etching, } \\
\text { SiN }_{\mathrm{x}} \text { interfacial } \\
\text { layer }\end{array}$ \\
\hline
\end{tabular}

Although not ideal, at present, sapphire is the most common substrate used for the epitaxial growth of $\mathrm{GaN}$ because of its low-cost and good thermal and chemical stability. The growth of III-nitride films on sapphire requires the implementation of a buffer layer to avoid performance degradation of the devices, induced by the high density of defects at the interface, resulted from the large mismatches in both the lattice and thermal expansion coefficient. [82] Other problems include the poor thermal conductivity of sapphire, that would impede heat dissipation reducing the lifetime of the device, and the dielectric characteristics of sapphire, which complicates the engineering procedure of devices such as LEDs, since the electric contact should be mounted on the front-side of the device. $[81,83]$

Silicon is a very attractive alternative due to its abundance, lowcost, mature wafer technology and excellent physical properties. In comparison to all the other substrate materials, Si substrates of large sizes are available at low-cost with high quality, greatly reducing the fabrication cost. However, the $\mathrm{GaN}$ and AlN films grown on Si possess low luminescence capacity and high defects concentration, due to the lattice mismatch and Si tendency to form amorphous $\mathrm{SiN}_{\mathrm{x}}$ at the interface. [84] Secondly, tensile stress originates from 
the mismatch in thermal expansion coefficient resulting in cracking of the $\mathrm{GaN}$ layers. [85] Thirdly, a so-called melt-back etching phenomenon between $\mathrm{Si}$ substrates and $\mathrm{Ga}$ atoms during the direct growth can result in poor-quality $\mathrm{GaN}$ films. [86] Lastly, a reduction in external quantum efficiency in devices grown on $\mathrm{Si}$ is observed, since the energy gap of $\mathrm{Si}(1.12 \mathrm{eV})$ is smaller than the wavelength of visible light and a large part of the light generated from the active region is absorbed by Si substrates [87].

Silicon carbide's advantages include a much smaller lattice mismatch, high thermal conductivity and simpler device fabrication since electrical conductivity is obtained through doping, allowing the mounting of the electric contacts on the back-side. The usage of $\mathrm{SiC}$ substrates is mainly limited by the fact that they are still expensive and not widely available. Moreover, the surface roughness and the fact that $\mathrm{SiC}$ is not wetted by $\mathrm{GaN}$ impose the necessity of a buffer layer. [88]

For taking advantage of the whole potential of group III-nitride materials, growth on new substrates should be developed in order to simplify device architecture, lower the cost, and take advantage of the different characteristic properties. A series of unconventional substrates, with low lattice and thermal mismatch, low-cost, or high thermal conductivity have been explored. The alternatives include metallic, oxide, or nearly lattice matched conductive templates/substrates. Metallic substrates for example, such as $\mathrm{Ti}$, $\mathrm{Mo}$, or $\mathrm{Cu}$, can have a small lattice mismatch, strong reflection of light, and thermal conductivity and lower the production cost since the cathode can be made directly on the substrate. Moreover, metallic substrates are more affordable in comparison with the commonly used substrates. [89] The thermal conductivity of the substrate must also be taken into account since device performance can be deteriorated if the generated local heat generated is not dissipated. Substrates with high thermal conductivity like $\mathrm{SiC}$ or graphene, [90] help address this problem. Moreover, by using metal seed layers grown on $\mathrm{SiC}$, the good thermal properties offered by $\mathrm{SiC}$ can be combined with the simplified device architecture, and electrical and optical properties of the metals. 


\subsection{Metalorganic Chemical Vapor Deposition}

MOCVD is a technique where growth takes place in thermodynamic equilibrium conditions by chemical reactions. [91] The metalorganic precursor molecules are carried away by a gas from a stainlesssteel container to an epitaxial growth chamber. The precursor can be in solid or liquid form and must exhibit an appropriate volatility and reactivity to thermally decompose inside the chamber. The most common precursors used for the growth of group III-nitrides are trimethylgallium (TMGa), triethylgallium (TEGa), trimethylaluminum (TMAl), and trimethylindium (TMIn), while ammonia is used as the source material for nitrogen. The general reaction that takes place can be described by:

$$
R 3 I I I-M+N H 3 \leftrightarrow I I I-M N+3 R H,
$$

where $\mathrm{R}$ represents the organic radical and III-M the group III-metal.

The growth process take place in four steps with gas input, pyrolysis, diffusion, and surface reaction. The by-products that result are then pumped away with the carrier gases. The precursors used, and the resulted residual gases, can have a negative impact for human health and environment. For dealing with this, a variety of exhaust systems are now available like scrubbing systems (which capture, isolate and convert pollutants before releasing into the environment) and burnboxes (where the unreacted gases are cracked and oxidized at high temperatures). [92]

\subsection{Molecular beam epitaxy}

MBE is a non-equilibrium growth method that employs the usage of Knudsen effusion cells or electron beam evaporators for heating and evaporating/sublimating source material under UHV conditions. For III-nitride semiconductor growth, typically the source material for nitrogen is ammonia or a nitrogen plasma and the compound is formed through the reaction between the group III metal and nitrogen at the substrate's surface. In this case, the reaction is kinetically driven by the surface processes, and is not a reaction taking place at thermodynamic equilibrium unlike MOCVD. [93] The resulting growth rates are relatively low compared to MOCVD. 


\subsection{Magnetron sputter epitaxy}

Sputtering is a physical vapor deposition taking place in a vacuum environment and consists in ejecting atoms from a target material by bombarding it with high energetic ions, followed by the condensation of these ejected atoms onto a substrate. Plasma is generating by introducing a working gas into the vacuum chamber and applying a negative potential on the target. The energy transferred to the target atoms by the colliding positive ions is described in equation 4.2. [94]

$$
\Lambda=\frac{4 M_{i} M_{t}}{\left(M_{i}+M_{t}\right)^{2}}
$$

where $\Lambda$ is the transferred energy, and $M_{i}$ and $M_{t}$ are the mass of the incident ion and target atom, respectively.

The interaction between the bombarding ions and target material generates not only sputtered atoms, but also secondary electrons, which are important for maintaining the plasma. A limitation of MBE and MOCVD growth consist in the high temperatures needed for obtaining high quality IIInitride materials. Due to the ion assisted growth which enhances adatom mobility, MSE allows for the growth of single-crystal, high-quality films even at room-temperature. [14] In MSE, the ionization process is enhanced by using a magnetic field. Reactive sputtering is when a reactive gas, like oxygen or nitrogen, is introduced into the sputtering chamber. The sputtered particles can undergo a chemical reaction with the reactive gas particles both before condensing onto the substrate and on the substrate surface. Therefore, the deposited material can be a compound, different from the metallic target material. The chemically reactive gas can react not only with the ejected atoms from the target, but also with the target surface. This phenomenon is called target poisoning and can cause instability to the process, if the hysteresis effect occurs. [95]

MSE has developed rapidly becoming the main sputtering process for obtaining a wide range of industrially important coatings. The applications include: hard, wear-resistant coatings, low friction coatings, corrosion-resistant coatings, decorative coatings, and coatings with special optical or electrical properties. [96] An important step was represented by the introduction of balanced magnetrons in the early 1970s. However, the process limitations were 
truly overcome with the development of the unbalanced magnetron in the late 1980s.

Depending on their magnetic field configuration three types of magnetrons can be defined (Figure 4.1).

- Balanced magnetron (center and outer poles have equal strength)

- Unbalanced magnetron type I (center pole is stronger than the outer pole)

- Unbalanced magnetron type II (outer pole is stronger than the inner pole). [97]

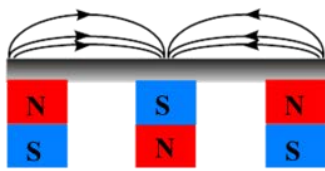

Balanced

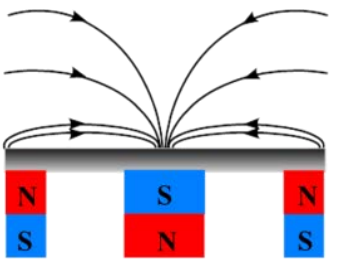

Unbalanced type I

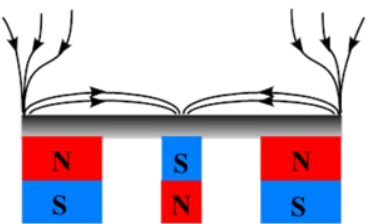

Unbalanced type II

Figure 4.1. Schematic illustration of the magnetron types and their magnetic field configuration.

The stronger magnets on the outside of an unbalanced magnetron results in an expanded plasma away from the surface of the target towards the substrate. The secondary electrons that escape the target's surface produce a greater number of ions closer to the substrate increasing the ion bombardment.

In DC sputtering, a potential difference is applied between target and substrate, leading to the acceleration of the gas ions towards the target's surface. Atoms are ejected from the target's surface and travel to the substrate surface where they are deposited.

Recently, high quality nitrides were grown by reactive magnetron sputtering from metallic targets under pure or diluted $\mathrm{N}_{2}$ sputtering gas. Argon or other inert gases are used to avoid the formation of a nitride layer on the target surface that can cause problems during deposition. The process of nitride formation consists in breaking the strong N-N bonds that can be stimulated by proper methods, such as increasing the substrate temperature and/or applying a negative potential to the substrate. Recently LEDs with sputtered $\mathrm{GaN} / \mathrm{InGaN} / \mathrm{GaN}$ active layers on glass substrates were demonstrated. GaN layers with clear $p$-type conductivity were grown at low temperature. These 
results cannot be obtained by classical MBE and MOCVD methods at such low temperatures, confirming MSE as a very promising technique for industrial integration. [98, 99]

\subsubsection{System description}

In this Thesis, GaN was grown in a UHV growth chamber, connected with the chamber used for $\operatorname{In}_{x} \mathrm{Al}_{1-\mathrm{x}} \mathrm{N}$ growth through a common loadlock and transfer tube system. This makes possible the future growth of nanorod heterostructures, without the need to vent the chamber every time during loading and unloading and exposing the sample to air. The scheme of the system is presented in figure 4.2. The base pressure inside the growth chamber is $1 \times 10^{-8}$ Torr. A liquid Ga target $(99.99999 \%$ pure) is placed in a stainless-steel crucible, in vertical position to avoid spilling. An enhanced ionization is achieved through the usage of a water cooled, type II unbalanced magnetron. [100]

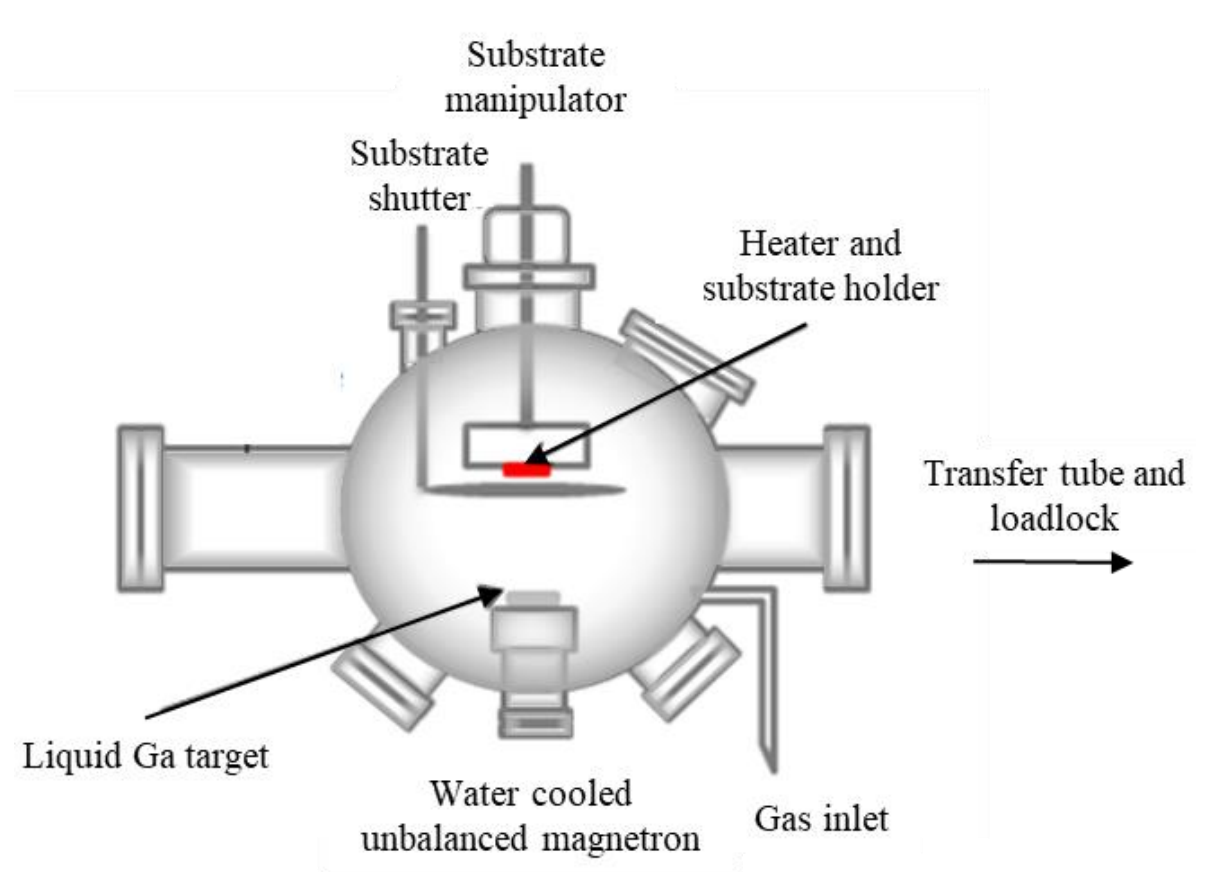

Figure 4.2. Schematic drawing of the growth chamber used for MSE of GaN. 
The sputtering system used for the growth of $\operatorname{In}_{\mathrm{x}} \mathrm{Al}_{1-\mathrm{x}} \mathrm{N}$ nanorods is represented in figure 4.3 , also with a base pressure of $1 \times 10^{-8}$ Torr. The system is equipped with four type II unbalanced magnetrons, corresponding to four metallic targets ( $\mathrm{Al}, \mathrm{In}, \mathrm{Ti}$, and $\mathrm{Sc}$ ), situated at approximately $13 \mathrm{~cm}$ from the substrate position with an inclination of $30^{\circ}$. [101]

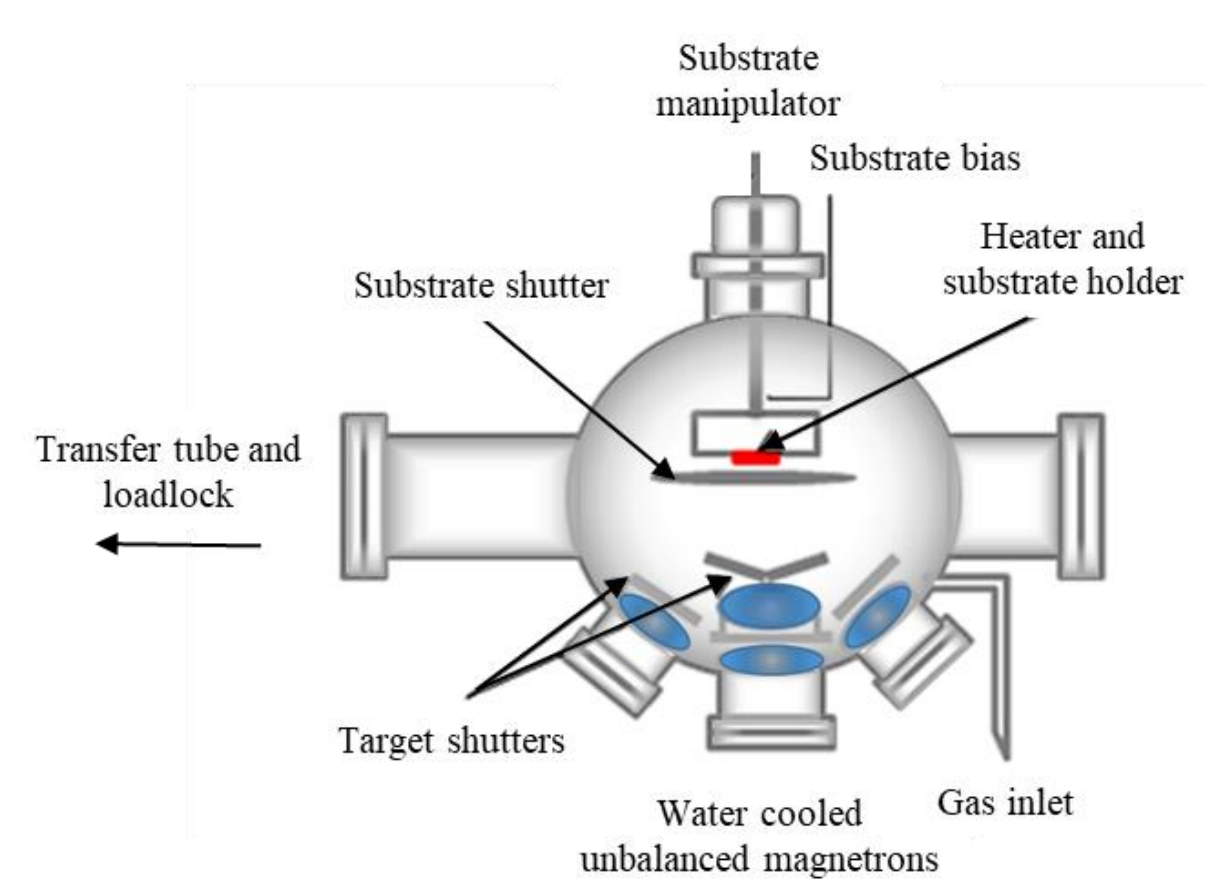

Figure 4.3. Schematic drawing of the growth chamber used for MSE of InAlN. 


\section{Characterization techniques}

\subsection{X-ray diffraction}

X-ray diffraction (XRD) is a non-destructive structural characterization technique. With the help of this technique, the most studied factors are: internal structure, chemical composition, stress, crystal orientation, crystal quality, crystal size, texture, lattice parameters, and surface and interface roughness.

X-rays typically have wavelengths similar to the spacing of lattice in crystals, in the range of a few $\AA$. They are generated by decelerating highly energetic electrons onto a target material (typically $\mathrm{Cu}$ ). The resulted characteristic $\mathrm{x}$-rays, typical $\mathrm{Cu}-\mathrm{K}_{\alpha}$ and $\mathrm{Cu}-\mathrm{K}_{\beta}$ line, are used as the light source in XRD measurement. Normally, $\mathrm{Cu}-\mathrm{K}_{\beta}$ line is filtered out by a Ni plate. The incident $\mathrm{x}$-ray scatters by the electron cloud surrounding each atom in the crystal, and constructive interference occurs between the scattered x-rays only if the path difference is an even number of wavelengths (Figure 5.1).

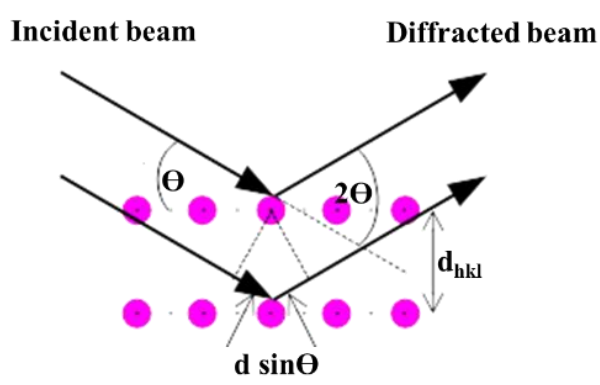

Figure 5.1. X-ray interaction with a crystal structure.

The diffraction of x-rays by different crystallographic planes in a crystal can be described using Bragg's law:

$$
n \lambda=2 d_{h k l} \sin \theta
$$

where, $\mathrm{n}$ is the diffraction order as an integer, $\lambda$ is the $\mathrm{x}$-ray wavelength, $\mathrm{d}_{\mathrm{hkl}}$ is the spacing between adjacent crystallographic planes with Miller indices hkl, 
and $\theta$ is the Bragg angle between incidence beam and crystal planes. In typical $\theta / 2 \theta$ scan, the angle between the incident beam and scattered beam is always kept as $2 \theta$.

The parameter $d_{h k l}$ is defined differently for each Bravais lattice, providing correlations between specific planes and Bragg angles for the wavelength of $\mathrm{x}$-ray, $\lambda$. For a hexagonal Bravais lattice the $d$ spacing is described by the equation:

$$
\frac{1}{d_{h k l}^{2}}=\frac{4}{3}\left(\frac{h^{2}+k^{2}+l^{2}}{a^{2}}\right)+\frac{1^{2}}{c^{2}} .
$$

\subsection{1 $\theta / 2 \theta$ scan}

In a symmetric scan, i.e. $\theta / 2 \theta$ scan, the reflected angle, $2 \theta$, is always kept as twice of incident angle, $\theta$, during measurement. Since the scattering vector is perpendicular to the surface, only the crystal planes parallel to the surface will contribute to Bragg's diffraction. A single-crystal sample would produce only one family of peaks in the diffraction pattern when measured in a $\theta / 2 \theta$ scan configuration. The diffraction pattern will contain a set of plane spacings, shown at various $2 \theta$ angles, and the corresponding relative intensities (I). The peak analysis can give the following information: peak

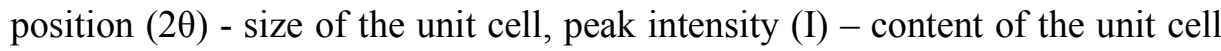
and broadening of the peaks - particle size and strain in the sample. A typical $\theta / 2 \theta$ diffraction pattern for single-crystal $\mathrm{GaN}$ nanorods grown on $\mathrm{Si}(111)$ substrate is presented in figure 5.2.

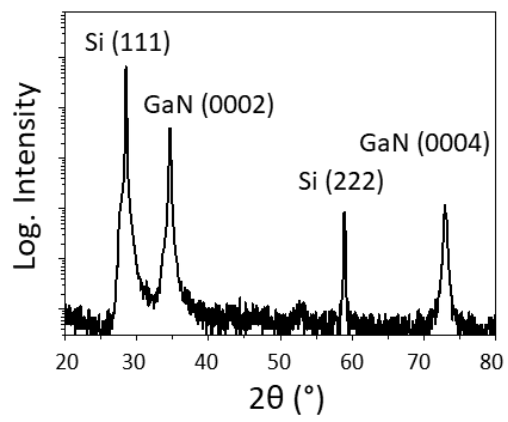

Figure 5.2. $\theta / 2 \theta$ of single-crystal $\mathrm{GaN}(0001)$ nanorods grown on $\mathrm{Si}(111)$ substrate.

The crystalline structures were characterized by $\theta / 2 \theta$ scan with a Philips 1820 Bragg- Brentano diffractometer using $\mathrm{Cu}-\mathrm{K}_{\alpha}$ radiation. 
Pole figure $\mathrm{XRD}$ is a common technique to obtain texture information. The pole figure is a stereographic projection representing a map of crystal directions with respect to the sample reference frame. The pole figure gives the probability of finding a given (hkl) plane, as a function of the specimen orientation. In a pole figure measurement, the sample reference frame is scanned by varying the $\varphi$ angle (twist angle around samples' normal direction) and $\Psi$ angle (tilt angle around samples' normal direction) at a fixed $2 \theta$ angle.

When the III-nitride associated reflexions join together forming a ring of higher intensity, it indicates that the nanorods have a fiber-texture with their $c$-axes along the growth direction and with random in-plane orientation (Figure 5.3a). When a treatment is applied to the substrate to remove the native oxide layer, such as HF etching or clean sputtering, the in-plane orientation of the III-nitride nanorods changes, exhibiting six distinct peaks, separated by $\varphi=$ $60^{\circ}$, and indicating an ordering in the in-plane orientation (Figure 5.3b).

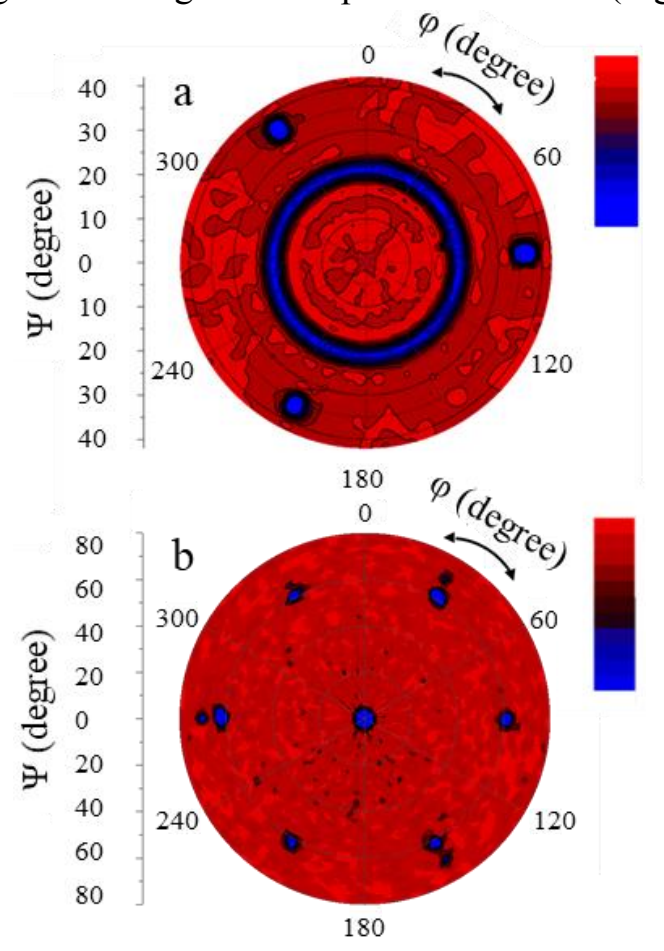

Figure 5.3. 10-15 pole figure of (a) randomly oriented, and (b) in-plane oriented GaN nanorods grown on Si substrate. 
For nanorods samples, the elongation along the phi $(\varphi)$ angle is attributed to a broad in-plane misorientation, meaning that the nanorods exhibits a small-angle twist with respect to each other. The elongation along psi ( $\Psi)$ angle is due to the tilted growth of the nanorods in respect to template's surface normal.

\subsection{Scanning Electron Microscopy}

The scanning electron microscope (SEM) is a powerful tool that utilizes a focused electron beam to obtain information by scanning it over a sample surface. The high-resolution three-dimensional images produced by SEM can provide topographical, morphological, and compositional information, which makes it invaluable in a variety of science and industry applications. [102]

Electron microscopes work on the same basic principles as optical microscopes, but use a focused beam of energetic electrons rather than photons in order to obtain higher magnified images of an object. The wavelength of the white light limits the resolution of the optical microscope to about 200-250 nm. Electrons have much shorter wavelengths, enabling better spatial resolution. The wavelength of accelerated electrons is described by the equation:

$$
\lambda=\frac{h}{\sqrt{2 m_{e} e V} \sqrt{1+\frac{e V}{2 m_{e} c^{2}}}},
$$

where $\mathrm{h}$ is Planck constant, $\mathrm{c}$ is the speed of light in vacuum, e is the electron charge, $\mathrm{V}$ is potential difference between anode and cathode, and $\mathrm{m}_{\mathrm{e}}$ is the electron mass.

The working principle is that a beam of electrons is produced at the top of the microscope by an electron gun. The electron beam follows a vertical path through a vacuum column where electromagnetic lenses focus the beam down toward the sample. Once the beam hits the sample, electrons and x-rays are ejected from the sample which are then analysed by appropriate detectors. The accelerated electrons carry significant amounts of kinetic energy and a variety of signals are produced by electron-sample interactions when the incident electrons are decelerated in the solid sample. These signals include secondary electrons (SE), backscattered electrons (BSE), diffracted backscattered electrons (used to determine crystal structures and orientations of 
minerals), characteristic x-rays (used for elemental analysis), photons (used in cathodoluminescence analysis), and heat. SE and BSE are used for imaging samples. SE are most valuable for showing morphology and topography (Figure 5.4). These emitted SE are detected with the "in-lens" detector. The edges and protruding parts look brighter than the rest of the image since more SE can leave the sample at edges (so-called edge effect).

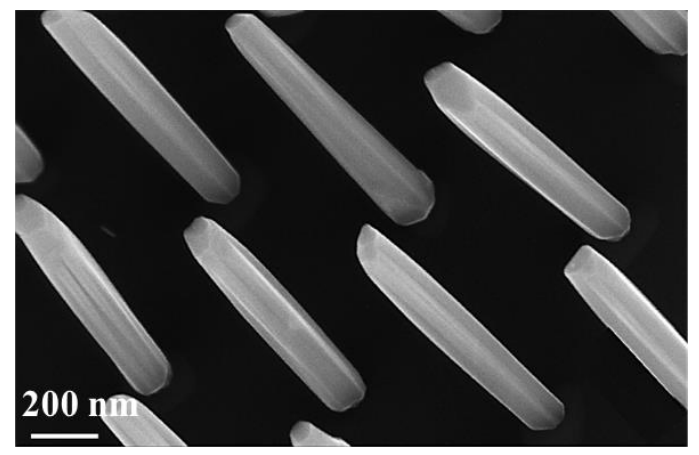

Figure 5.4. Tilt-view SEM image on SAG GaN nanorods.

\subsection{Cathodoluminescence spectroscopy}

In this technique, the signal consists in cathodoluminescence (CL) emission by a sample on which an electron beam is focused. Photons are emitted due to the radiative recombination resulted from the excitation of the electrons of the material analysed, in the conduction band under electron beam irradiation.

A detector can produce high-resolution cathodoluminescent images of luminescent materials and it can be attached to a SEM or a transmission electron microscope (TEM). CL is a common technique used for group III materials, since they possess high radiative recombination (Figure 5.5), to analyse the bandgap and intermediate band (impurity and/or defect). CL emission can be enhanced with higher beam voltage and current, however, resulting in sample heating and charging effects.

In this Thesis, sample morphologies were characterized with a Zeiss Leo 1550 field-emission gun SEM. The SEM is equipped with a Gatan MonoCL4 spectroscope, used for performing room-temperature cathodoluminescence $(\mathrm{CL})$ spectroscopy and mapping. The acceleration voltage of the electron beam was set as $10 \mathrm{kV}$. The emission from the samples is 
dispersed by a monochromator with a 150 lines $/ \mathrm{mm}$ grating blazed at $500 \mathrm{~nm}$ and detected by a Peltier-cooled photomultiplier tube
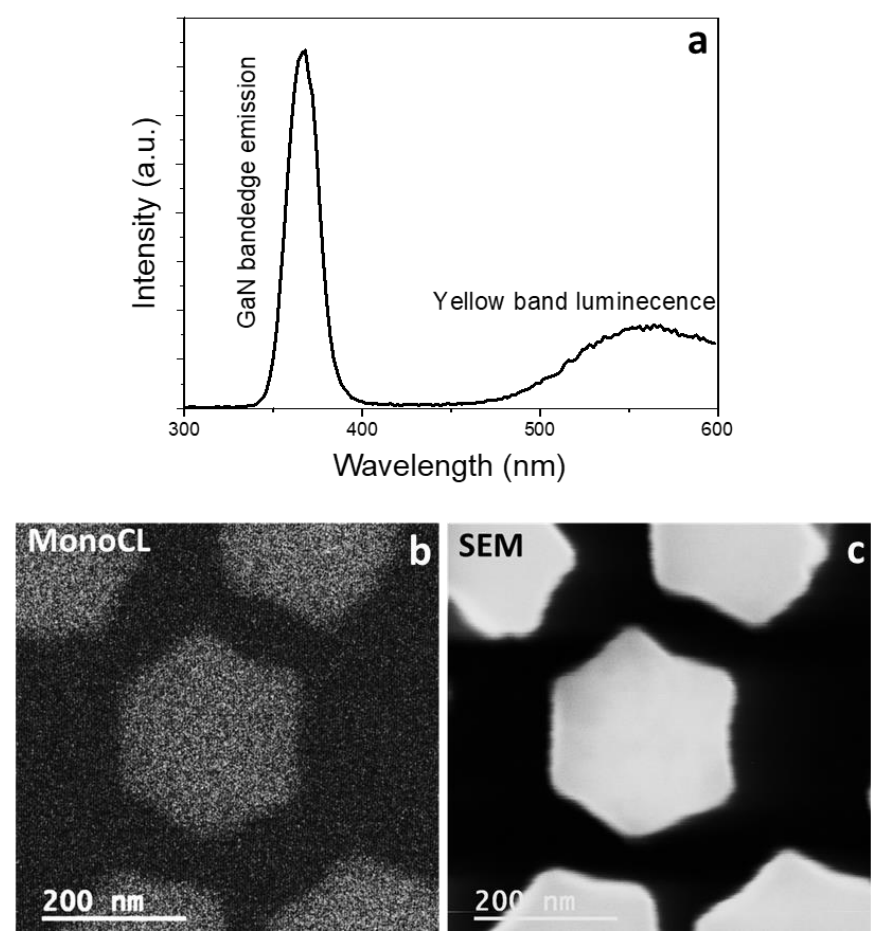

Figure 5.5. a) A typical room-temperature CL spectrum of GaN nanorods, b) monochromatic CL image of GaN nanorods recorded at $365 \mathrm{~nm}$ (bandedge emission) and c) the corresponding SEM image.

\subsection{Transmission electron microscopy}

In a transmission electron microscope, the electrons generated by an electron gun are accelerated and go through the illumination system composed of two or more sets of electro-magnetic condenser lenses. An electron-transparent sample is irradiated by electrons with energies of the order of 100-300 kV. After the interaction with the sample, the electrons are either transmitted, scattered, or reflected. The transmitted and scattered electrons enter the imaging system of the microscope composed of the objective, intermediate, and projector magnetic lenses. The resulting image can be visualized on a fluorescent screen and recorded with the help of a CCD-camera. The TEM 
specimens must be sufficiently thin $(\sim 100 \mathrm{~nm})$ to allow transmission of electrons. TEM provides information regarding the crystal structure of the specimen, like: microstructure, crystal structure and position of the atoms in the crystal, but also about composition through elemental mapping.

The standard TEM imaging modes are bright-field and dark-field imaging (Figure 5.6). In the bright-field operation mode the objective aperture is place so that only the transmitted beam is allowed to pass forming the image. This way, the parts of the sample that scatter more have less intensity, appearing darker in the image. Dark-field images are formed when the objective aperture is placed so that only one diffracted beam is allowed to pass. In this case, the parts of the sample that have a high scattering become brighter in the image.

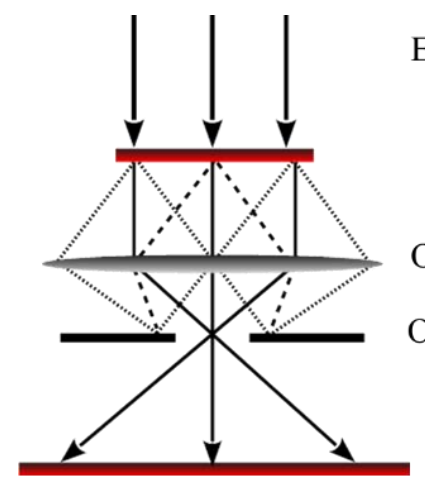

Bright-field image

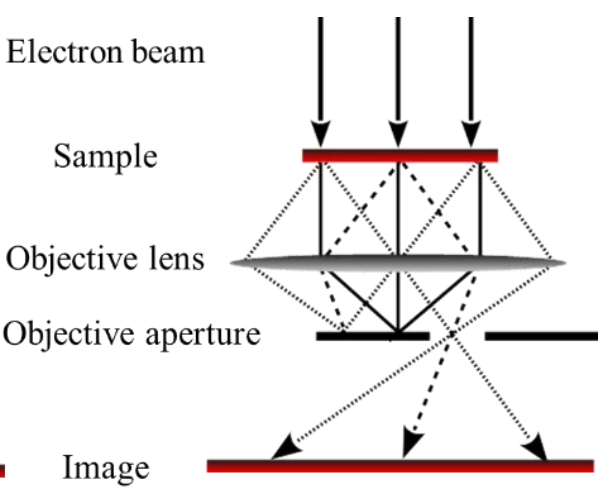

Dark-field image

Figure 5.6. Diagram of standard TEM imaging modes.

In high-resolution TEM (HRTEM), an image of the crystal lattice is obtained by interference of transmitted beam and diffracted beams.

TEM can be operated in the microprobe mode, i.e. the illumination is parallel on the sample, or nanoprobe mode, i.e. a nanometric spot size is obtained by a convergent beam illumination. Microprobe is used in TEM and electron diffraction analysis to illuminate large areas. Nanoprobe is used for spectroscopic techniques: electron energy loss spectroscopy (EELS) and energy-dispersive $\mathrm{x}$-ray spectroscopy (EDX), and for imaging by scanning TEM (STEM).

In STEM, a nanoprobe is scanned across the surface of the specimen, and the diffracted electrons are registered with a detector placed at the end of the column. This way, the contrast in STEM mode is determined by 
the scattering angle. Electrons scattered at an intermediate angle can be probed with an annular dark-field detector (ADF) and will result in a diffraction dominated contrast. Electrons scattered at large angles can be probed with a high-angle annular dark-field (HAADF) detector, and the contrast will be influenced by the atomic number of the species in the analysed sample. The ADF detector can also be used as an annular detector within the bright-field $(\mathrm{ABF})$ region detecting the "shell" of the direct-beam. The ABF detector is particularly useful for detection of lighter atoms with extremely weak scattering, due to phase-contrast imaging based on wave interference, like oxygen, nitrogen, or lithium atoms.

Another type of interaction after the samples' irradiation with the electron beam results from the ejection of a core electron and the decay of the excited atom to its ground state by emitting characteristic x-rays. Elemental composition can be probed by measuring the characteristic x-rays by an EDX spectrometer (Figure 5.7).

Microstructural analyses were performed by using the doublecorrected Linköping FEI Titan ${ }^{3}$ 60-300, operated at $300 \mathrm{kV}$.
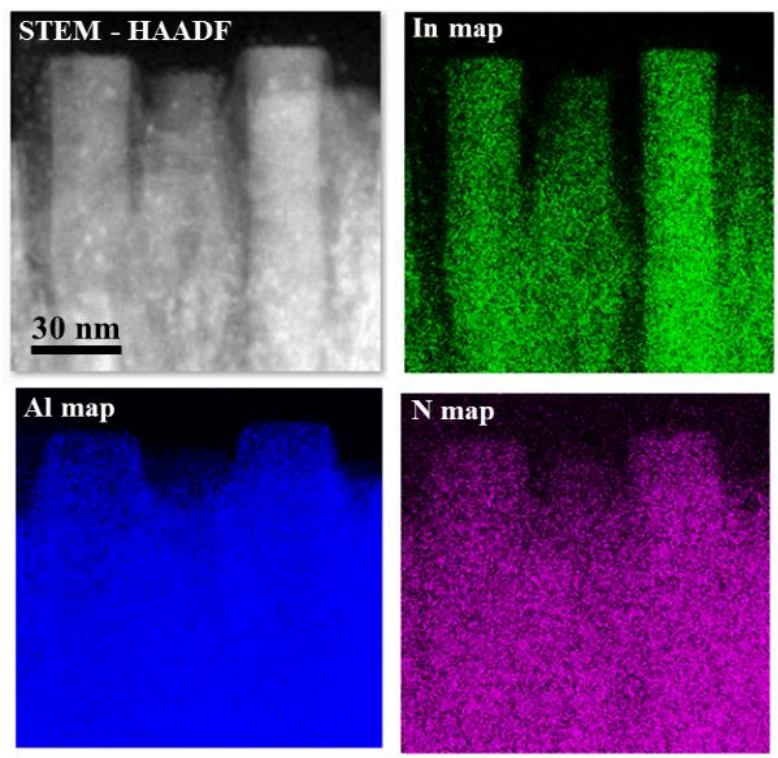

Figure 5.7. STEM-HAADF image and corresponding EDX elemental mappings of core-shell $\operatorname{In}_{\mathrm{x}} \mathrm{Al}_{1-\mathrm{x}} \mathrm{N}$ nanorods. 


\section{Summary and contributions to the field}

The included results present the growth and characterization of group III-nitride semiconductor nanorods, namely InAlN and GaN nanorods. All the nanostructures were grown by employing direct-current reactive magnetron sputter epitaxy. The growth study and characterisation of both selfassembled and selective-area grown nanorods are presented.

The growth of $\boldsymbol{I n}_{x} \boldsymbol{A} \boldsymbol{l}_{1-x} \boldsymbol{N}$ radial nanorod heterostructures on $\mathrm{Si}(111)$ substrates using direct current reactive MSE was demonstrated. No catalyst was used for the growth of $\operatorname{In}_{x} \mathrm{Al}_{1-\mathrm{x}} \mathrm{N}$ core-shell nanorods. The temperature effect upon the morphology and composition of the nanorods was investigated by SEM, XRD, STEM, and EDX mapping. The spontaneous formation of core-shell nanorods, consisting of In-rich cores surrounded by Alrich shells with different thicknesses was observed. The nanorod diameter and shell thickness increase with the increase in growth temperature. It was revealed that lower growth temperatures induce the formation of well-separated and uniform core-shell nanorods with high In-content cores $\left(700-800{ }^{\circ} \mathrm{C}\right)$, while a deposition at higher temperature $\left(850^{\circ} \mathrm{C}\right)$ leads to the formation of an $\mathrm{Al}$-rich $\mathrm{In}_{x} \mathrm{Al}_{1-x} \mathrm{~N}$ film resulted from the coalescence of core-shell nanorods. The formation of the nanostructures was traced to the initial growth. A correlation between the influence of the substrate treatment upon the formation of the interfacial layer and crystallographic relationship was reported. By applying the treatment to the substrate, the in-plane fiber-textured growth of the nanorods was modified to an epitaxial growth.

The versatility of MSE in achieving high-quality GaN nanorods was demonstrated by the growth of self-assembled GaN nanorods by employing different substrate/template combinations, specifically $\mathrm{Si}, \mathrm{SiC}$, $\mathrm{TiN} / \mathrm{Si}, \mathrm{ZrB}_{2} / \mathrm{Si}, \mathrm{ZrB}_{2} / \mathrm{SiC}, \mathrm{Mo}$, and Ti. Growth temperature was optimized resulting in increased nanorod aspect ratio. The decrease of the diffusion length with increased temperature was observed, in agreement with established models. High-resolution TEM and CL studies revealed nanorods with strong bandedge emission resulting from their high purity and quality, especially for $\mathrm{GaN}$ nanorods grown on TiN/Si. Non-conventional substrates are not only costeffective but also eliminate post-processing steps in device fabrication. 
The first successful SAG of single-crystal wurtzite GaN nanorods by reactive MSE was realised. The $\mathrm{Si}(001)$ substrates with un-etched native

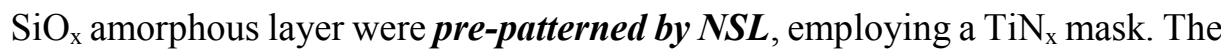
growth temperature (in the range $875-985^{\circ} \mathrm{C}$ ) effect upon morphology was studied. Selectivity was achieved starting from $925{ }^{\circ} \mathrm{C}$ and the increase in temperature resulted in nanorods with an improved aspect ratio, exhibiting reduced diameters and increased lengths. This trend is terminated at $985{ }^{\circ} \mathrm{C}$, when the process is governed by desorption and no nanorod growth occurs. The initial growth stages and the time evolution of SAG GaN(0001) nanorods were studied, based on observations from samples grown for different sputtering times. With the help of characterization techniques like SEM, XRD, TEM STEM, and EDX, a 5-step growth model was defined. The growth mechanism steps are: formation of a polycrystalline wetting layer, predominating $c$-axis oriented nucleation, coarsening and coalescence of multi-islands, single nanorod evolution, and finally quasi-equilibrium crystal shape formation. Our SAG-GaN nanorods possess strong bandedge emission with uniform luminescence as seen by room-temperature CL analysis. Moreover, singlelongitudinal-mode lasing was obtained at room-temperature by optical pumping with a pulsed laser. The lasing characteristics are attributed to well-faceted nanorod geometry forming a Fabry-Pérot cavity, proving the high potential of MSE for fabricating high-performance laser optoelectronics.

Finally, the growth conditions of NSL GaN nanorods were transferred on FIBL-patterned substrates which offers more control on the nanorod sizes and positions. FIBL optimization included tailoring of the milling current (2$50 \mathrm{pA}$ ) and milling time (5-50 s). Low milling currents are necessary to avoid damage to the whole mask layer. A minimum ion beam-induced substrate damage is achieved at low currents of $2 \mathrm{pA}$ and short milling times. Longer milling times induce extensive substrate damage, as observed by STEM and EDX mapping, which conducts to the growth of multiple, tilted nanorods inside one opening. Growth temperature optimization was also performed. At lower growth temperatures $\left(950^{\circ} \mathrm{C}\right)$ nanostructures resulted from the coalescence of multiple, tilted nanorods are observed. The tilting of the nanorods is reduced when increasing the growth temperature to $980{ }^{\circ} \mathrm{C}$. In these patterning conditions growth results in single, straight nanorods with uniform sizes, and only in the designated positions. The optimum growth conditions were further explored by realising a pressure-dependent series. $\mathrm{Ar} / \mathrm{N}_{2}$ mixture was used as a working gas and the amount of Ar introduced was varied between 0 and 50\%. 
The transition of the target from a nitridized state to more metallic causes the sputtering conditions to change. In $\mathrm{N}$-rich conditions - pure $\mathrm{N}_{2}$ working gas or a mixture with sufficiently small amounts of $\operatorname{Ar}(5 \%)$, selectivity is poor, up to $50 \%$ of the total number or nanorods nucleating on the mask layer. Bimodal diameter distributions are observed, with two maxima corresponding to the SAG nanorods from the openings, and SA nanorods from the mask layer with small average sizes. By diluting the reactive gas with more $\mathrm{Ar}(10 \%)$ growth selectivity and coalescence are promoted, and the nanorods are uniform in size with a narrow diameter distribution. With increasing the Ar amount, the growth takes placed in a transitional regime defined by the competition between a target covered with a thin GaN layer and a metallic- target causing change in sputtering conditions. Finally, at $50 \%$ Ar, the target is in metallic-state. In these sputtering conditions, a high density of uncoalesced nanorods with low axial growth rate due to the limited supply of reactive $\mathrm{N}$-species, result inside the openings. The partial pressure variation gave full control upon the selectivity, morphology, and diffusion enabling the long-time growth of well-defined, single, uniform, and straight nanorods.

It has been proved that MSE is a versatile method which offers high industrial applicability and for the future work the technique should be extended to develop different structures. The work presented in this Thesis on optimizing SAG of nanorods, can be used as a fundament for combining the properties of the materials presented in the form of single nanorods, by developing axial and radial heterostructures, in both a SA or SAG manner. Another interesting approach would be to integrate quantum dots inside the nanorods, especially in the case of the very thin GaN nanorods grown on TiN seed layers. Last but not least, the utility of the obtained materials and structures should be proven by integration into devices and testing their capabilities. 


\section{References}

1. O-S-D Report-A market analysis and forecast for optoelectronics, sensors/actuators, and discretes, (2016).

2. O. Ambacher. "Growth and applications of group III-nitrides", J. Phys. D: Appl. Phys. 31, 2653 (1998).

3. I. Akasaki, H. Amano, M. Kito, and K. Hiramatsu. "Photoluminescence of Mg-doped p-type GaN and electroluminescence of $\mathrm{GaN}$ p-n junction LED”, J. Lumin. 48 \& 49, 666 (1991).

4. S. Nakamura, M. Senoh, S. Nagahama, N. Iwasa, T. Yamada, T Matsushita, H. Kiyoku, and Y. Sugimoto. "InGaN-based multi-quantumwell-structure laser diodes", Jpn. J. Appl. Phys. 35, L74 (1996).

5. H.P. Maruska, and W.C. Rhines. "A modern perspective on the history of semiconductor nitride blue light sources”, Solid-State Electron. 111, 32 (2015).

6. H. Amano, N. Sawaki, and I. Akasaki. "Metalorganic vapor phase epitaxial growth of a high quality GaN film using an AlN buffer layer", Appl. Phys. Lett. 48, 353 (1986).

7. H. Amano, M. Kito, K. Hiramatsu, and I. Akasaki. "P-type conduction in Mg-doped GaN treated with low-energy electron beam irradiation (LEEBI)", Jpn. J. Appl. Phys. 28, L2112 (1989).

8. Z. Liu, X. Yi, Z. Yu, G. Yuan, Y. Liu, J. Wang, J. Li, N. Lu, I. Ferguson, and Y. Zhang. "Impurity resonant states p-type doping in wide-band-gap nitrides", Sci. Rep. 6, 19537 (2016).

9. T. Mukai, M. Yamada, and S. Nakamura. "Characteristics of InGaNbased UV/blue/green/amber/red light-emitting diodes", Jpn J. Appl. Phys. 38, 3976 (1999).

10. S. Zhaoa, H.P.T. Nguyenb, M.G. Kibriaa, and Z. Mi. "III-Nitride nanowire optoelectronics", Prog. Quant. Electron. 44, 14 (2015).

11. M. Sanchez-Garcia, E. Calleja, E. Monroy, F. Sanchez, F. Calle, E. Muñoz, and R. Beresford., "The effect of the III/V ratio and substrate temperature on the morphology and properties of GaN-and AlN-layers grown by molecular beam epitaxy on $\mathrm{Si}(111)$ ", J. Cryst. Growth 198, 23 (1998). 
12. M. Yoshizawa, A. Kikuchi, N. Fujita, K. Kushi, H. Sasamoto, and K. Kishino. "Self-organization of $\mathrm{GaN} / \mathrm{Al}_{0.18} \mathrm{Ga}_{0.82} \mathrm{~N}$ multi-layer nanocolumns on (0001) $\mathrm{Al}_{2} \mathrm{O}_{3}$ by $\mathrm{RF}$ molecular beam epitaxy for fabricating GaN quantum disks", J. Cryst. Growth 189-190, 138 (1998).

13. C.-L. Hsiao, J. Palisaitis, M. Junaid, P.O.Å. Persson, J. Jensen, Q.-X. Zhao, L. Hultman, L.-C. Chen, K.-H. Chen, and J. Birch. "Roomtemperature heteroepitaxy of single-phase $\mathrm{Al}_{1-\mathrm{x}} \mathrm{In}_{\mathrm{x}} \mathrm{N}$ films with full composition range on isostructural wurtzite templates", Thin Solid Films 524, 113 (2012).

14. J. Birch, S. Tungasmita, and V. Darakchieva. "Magnetron sputter epitaxy of AlN", Vacuum science and technology: nitrides as seen by the technology, 456 (2002).

15. M. Junaid, C.-L. Hsiao, J. Palisaitis, J. Jensen, P.O.A Persson, L. Hultman, and J. Birch. "Electronic-grade $\mathrm{GaN}(0001) / \mathrm{Al}_{2} \mathrm{O}_{3}(0001)$ grown by reactive DC-magnetron sputter epitaxy using a liquid Ga target", Appl. Phys. Lett. 98, 141915 (2011).

16. M. Junaid, Y.-T. Chen, J. Palisaitis, M. Garbrecht, C.-L. Hsiao, P.O.Å Persson, L. Hultman, J. Birch. "Liquid-target reactive magnetron sputter epitaxy of high quality GaN(0001) nanorods on Si(111)", Mater. Sci. Semicond. Process. 39, 702 (2015).

17. C.-L. Hsiao, J. Palisaitis, P.O.Å. Persson, M. Junaid, E.A. Serban, P. Sandström, L. Hultman, and J. Birch. "Nucleation and core-shell formation mechanism of self-induced $\operatorname{In}_{\mathrm{x}} \mathrm{A} 1_{1-\mathrm{x}} \mathrm{N}$ core-shell nanorods grown on sapphire substrates by magnetron sputter epitaxy", Vacuum 131, 39 (2016).

18. C.-L. Hsiao, R. Magnusson, J. Palisaitis, P. Sandström, P.O.A. Persson, V. Sergiy, L. Hultman, K. Järrendahl, and J. Birch. "Curved-lattice epitaxial growth of $\operatorname{In}_{\mathrm{x}} \mathrm{Al}_{1-\mathrm{x}} \mathrm{N}$ nanospirals with tailored chirality", Nano Lett. 1, 294 (2015).

19. G.Z. Radnóczi, T. Seppänen, B. Pécz, L. Hultman, and J. Birch. "Growth of highly curved $\mathrm{Al}_{1-\mathrm{x}} \mathrm{In}_{\mathrm{x}} \mathrm{N}$ nanocrystals", Phys. Stat. Sol. A 202, R76 (2005).

20. D. Vogel, P. Kruger, and J. Pollmann. "Structural and electronic properties of group-III nitrides", Phys. Rev. B 55, 12836 (1997).

21. R. Collazzo, and N. Dietz. "Photoelectrochemical water splitting: Materials, processes and architectures, Chapter 8: The group III-nitride 
material class: from preparation to perspectives in photoelectrocatalysis", The Royal Society of Chemistry (2014), ISBN: 9781849736473.

22. B. Gil. "Group III-nitride semiconductor compounds: Physics and applications", Clarendon Press (1998), ISBN: 9780198501596

23. A. Zoroddu, F. Bernardini, P. Ruggerone, and V. Fiorentini. "Firstprinciples prediction of structure, energetics, formation enthalpy, elastic constants, polarization, and piezoelectric constants of $\mathrm{AlN}, \mathrm{GaN}$, and InN: Comparison of local and gradient-corrected density-functional theory", Phys. Rev. B 64, 045208 (2001).

24. B. Daudin, J.L. Rouvière, and M. Arlery. "Polarity determination of GaN films by ion channeling and convergent beam electron diffraction", Appl. Phys. Lett. 69, 2480 (1996).

25. M. Sumiya, and S. Fuke. "Review of polarity determination and control of GaN", MRS Internet J. N. S. R. 9, 1 (2004).

26. H. Okumura, M. Shimizu, X. Qiang, and S. Toshihide. "Polarity control in MBE growth of III-nitrides, and its device application", Curr. Appl. Phys. 2, 305 (2002).

27. P. Reddy, I. Bryan, Z. Bryan, W. Guo, L. Hussey, R. Collazo, and Z. Sitar. "The effect of polarity and surface states on the Fermi level at III-nitride surfaces", J. Appl. Phys. 116, 123701 (2014).

28. A. Bao. "Group III-nitride nanowires", Mater. Sci. Technol. 33, 765 (2017).

29. L. Jinmin, L. Zhe, L. Zhiqiang, Y. Jianchang, W. Tongbo, Y. Xiaoyan, and W. Junxi. "Advances and prospects in nitrides based light emittingdiodes", J. Semicond. 37, 061001 (2016).

30. C. Chen, K. H. Chen, and C.-C. Chen. "Nanowires and nanobelts, Chapter 9: Group III- and group IV-nitride nanorods and nanowires" Springer (2003), ISBN: 9780387287058

31. P. Ramvall, S. Tanaka, S. Nomura, P. Riblet, and Y. Aoyagi. "Observation of confinement-dependent exciton binding energy of GaN quantum dots", Appl. Phys. Lett. 73, 1104 (1998).

32. H. Yu, J. Li, R.A. Loomis, L.-W. Wang, and W.E. Buhro. "Two- versus three-dimensional quantum confinement in indium phosphide wires and dots", Nat. Mater. 2, 517 (2003).

33. A. Dong, H. Yu, F. Wang, and W.E. Buhro. "Colloidal GaAs quantum wires: solution-liquid-solid synthesis and quantum-confinement studies", J. Am. Chem. Soc. 130, 5859 (2008). 
34. S. Arafin, X. Liu, and Z. Mi. "Review of recent progress of III-nitride nanowire lasers", J. Nanophoton. 7, 074599 (2013).

35. M.S. Kang, C.-H. Lee, J.B. Park, H. Yoo, and G.-C. Yi. "Gallium nitride nanostructures for light-emitting diode applications”, Nano Energy 1, 391 (2012).

36. G. Meneghesso, M. Meneghini, I. Rossetto, D. Bisi, S. Stoffels, M. Van Hove, S. Decoutere, and E. Zanoni. "Reliability and parasitic issues in GaN-based power HEMTs: A review", Semicon. Sci. Technol. 31, 093004 (2016).

37. S. Chattopadhyay, A. Ganguly, K.-H. Chen, and L.-C. Chen. "Onedimensional group III-nitrides: Growth, properties, and applications in nanosensing and nano-optoelectronics", Crit. Rev. Solid State 34, 224 (2009).

38. U. Chatterjee, J.-H. Park, D.-Y. Um, and C.-R. Lee. "III-nitride nanowires for solar light harvesting: A review", Renewable Sustainable Energy Rev. 79, 1002 (2017).

39. N. Gogneau, N. Jamond, P. Chrétien, F. Houzé, E. Lefeuvre, and M. Tchernycheva. "From single III-nitride nanowires to piezoelectric generators: New route for powering nomad electronics", Semicon. Sci. Technol. 31, 103002 (2016).

40. D. Tsokkou, A. Othonos, and M. Zervos. "Defect states of chemical vapor deposition grown GaN nanowires: Effects and mechanisms in the relaxation of carriers", J. Appl. Phys. 106, 054311 (2009).

41. D.K.T. Ng, M. Hong, L.S. Tan, Y. Wang, G. Chen, and C.J. Lua. "Fabrication of gallium nitride nanocones arrays on silicon by pulsed laser ablation using anodic aluminum oxide mask", J. Laser Micro Nanoeng. 1, 115 (2006).

42. J. Su, G. Cui, M. Gherasimova, H. Tsukamoto, J. Han, D. Ciuparu, S. Lim, L. Pfefferle, Y. He, A.V. Nurmikko, C. Broadbridge, and A. Lehman. "Catalytic growth of group III-nitride nanowires and nanostructures by metalorganic chemical vapor deposition", Appl. Phys. Lett. 86, 013105 (2005).

43. J. Ristic, E. Calleja, S. Fernandez-Garrido, L.Cerutti, A. Trampert, U. Jahn, and K.H. Ploog. "On the mechanisms of spontaneous growth of IIInitride nano-columns by plasma-assisted molecular beam epitaxy", $J$. Cryst. Growth 310, 4035 (2008). 
44. A. Trassoudaine, E. Roche, C. Bougerol, Y. André, G. Avit, G. Monier, M.R. Ramdani, E. Gil, D. Castelluci, and V.G. Dubrovskii, "Spontaneous formation of GaN/AlN core-shell nanowires on sapphire by hydride vapor phase epitaxy", J. Cryst. Growth 454, 1 (2016).

45. K. Yamano, and K. Kishino. "Selective area growth of InGaN-based nanocolumn LED crystals on AlN/Si substrates useful for integrated $\mu$ LED fabrication", Appl. Phys. Lett. 112, 091105 (2018).

46. A.T.M Golam Sarwar, B.J. May, M.F. Chisholm, G.J. Duscher, and R.C. Myers. "Ultrathin GaN quantum disk nanowire LEDs with sub-250 nm electroluminescence", Nanoscale 8, 8024 (2016).

47. S.Y. Woo, N. Gauquelin, H.P.T. Nguyen, Z. Mi, and G.A. Botton. "Interplay of strain and indium incorporation in InGaN/GaN dot-in-awire nanostructures by scanning transmission electron microscopy", Nanotechnology 26, 344002 (2015).

48. I. Gîrgel, A. Šatka, J. Priesol, P.-M. Coulon, E.D. Le Boulbar, T. Batten, D.W.E. Allsopp, and P.A. Shields. "Optical characterization of magnesium incorporation in $p$-GaN layers for core-shell nanorod lightemitting diodes", J. Phys. D: Appl. Phys. 51, 155103 (2018).

49. M. Mandl, X. Wang, T. Schimpke, C. Kölper, M. Binder, J. Ledig, A. Waag, X. Kong, A. Trampert, F. Bertram, J. Christen, F. Barbagini, E. Calleja, and M. Strassburg. "Group III-nitride core-shell nano- and microrods for optoelectronic applications", Phys. Status Solidi RRL 7, 800 (2013).

50. M. Gómez-Gómez, N. Garro, J. Segura-Ruiz, G. Martinez-Criado, A. Cantarero, H.T. Mengistu, A. García-Cristóbal, S. Murcia-Mascarós, C. Denker, J. Malindretos, and A. Rizzi. "Spontaneous core-shell elemental distribution in In-rich $\operatorname{In}_{\mathrm{x}} \mathrm{Ga}_{1-\mathrm{x}} \mathrm{N}$ nanowires grown by molecular beam epitaxy", Nanotechnology 25, 075705 (2014).

51. R.G. Hobbs, N. Petkov, and J.D. Holmes. "Semiconductor nanowire fabrication by bottom-up and top-down paradigms", Chem. Mater. 24, 1975 (2012).

52. S. Barth, F. Hernandez-Ramirez, J. D. Holmes, and A. RomanoRodriguez. "Synthesis and applications of one-dimensional semiconductors", Progr. Mater. Sci. 55, 563 (2010).

53. R.S. Wagner, and W.C. Ellis. "Vapor-liquid-solid mechanism of single crystal growth", Appl. Phys. Lett. 4, 89 (1964). 
54. C. Chèze, L. Geelhaar, O. Brandt, W.M. Weber, H. Riechert, S. Münch, R. Rothemund, S. Reitzenstein, A. Forchel, T. Kehagias, P.Komninou, G.P. Dimitrakopulos, and T. Karakostas. "Direct comparison of catalystfree and catalyst-induced GaN nanowires", Nano Res. 3, 528 (2010).

55. V. Consonni. "Self-induced growth of GaN nanowires by molecular beam epitaxy: A critical review of the formation mechanisms", Phys. Status Solidi RRL 7, 699 (2013).

56. B. Foltynski, C. Giesen, and M. Heuken. "Self-organized growth of catalyst-free $\mathrm{GaN}$ nano- and microrods on $\mathrm{Si}(111)$ substrates by MOCVD”, Phys. Status Solidi B 252, 1132 (2015).

57. J. Palisaitis, C.-L. Hsiao, L. Hultman, J. Birch, and P.O.Å. Persson. "Core-shell formation in self-induced InAlN nanorods", Nanotechnology 28, 115602 (2017).

58. H. Li, L. Geelhaar, H. Riechert, and C. Draxl. "Computing equilibrium shapes of wurtzite crystals: the example of GaN", Phys. Rev. Lett. 115, 085503 (2015).

59. Ga evi , D.G. S nchez, and E. Calleja. "Formation mechanisms of GaN nanowires grown by selective area growth homoepitaxy", Nano Lett. 15, 1117 (2015).

60. P.M. Coulon, B. Alloing, V. Brändli, D. Lefebvre, S. Chenot, and J. Zúñiga-Pérez. "Selective area growth of Ga-polar GaN nanowire arrays by continuous-flow MOVPE: A systematic study on the effect of growth conditions on the array properties", Phys. Status Solidi B 252, 1096 (2015).

61. S. Albert, A. Bengoechea-Encabo, M.A. Sanchez-Garcia, E. Calleja, and U. Jahn. "Selective area growth and characterization of $\mathrm{InGaN}$ nanocolumns for phosphor-free white light emission", J. Appl. Phys. 113, 114306 (2013).

62. S.D. Hersee, X. Sun, and X. Wang. "The controlled growth of GaN nanowires", Nano Lett. 6, 1808 (2006).

63. T. Schumann, T. Gotschke, F. Limbach, T. Stoica, and R. Calarco. "Selective-area catalyst-free MBE growth of $\mathrm{GaN}$ nanowires using a patterned oxide layer", Nanotechnology 22, 095603 (2011).

64. R. F. Pease, and S. Y. Chou. "Lithography and other patterning techniques for future electronics," Proc. IEEE 96, 248 (2008). 
65. P. Colson, C. Henrist, and R. Cloots. "Nanosphere lithography: A powerful method for the controlled manufacturing of nanomaterials," $J$. Nanomater. 2013, 948510 (2013).

66. A. Pimpin, and W. Srituravanich. "Review on micro- and nanolithography techniques and their applications", Eng. J. 16, 37 (2012).

67. H.D. Wanzenboeck, and S. Waid. "Focused ion beam lithography, recent advances in nanofabrication techniques and applications", (2011), ISBN: 9789533076027.

68. F. Barbagini, A. Bengoechea-Encabo, S. Albert, J. Martinez, M.A. Sanchez García, A. Trampert, and E. Calleja. "Critical aspects of substrate nanopatterning for the ordered growth of GaN nanocolumns", Nanoscale Res. Lett. 6, 632 (2011).

69. Al. Joshi-Imre, and S. Bauerdick. "Direct-write ion beam lithography", $J$. Nanotechno. 2014, 170415 (2014).

70. P. Naulleau. "Nanofabrication handbook, Chapter 6: Optical lithography", CRC Press (2012), ISBN: 9781420090536.

71. N. Guillot, and M. L. de la Chapelle. "Lithographied nanostructures as nanosensors", J. Nanophotonics 6, 064506 (2012).

72. S. Naureen. "Top-down fabrication technologies for high-quality II-IV nanostructures" (2013) ISBN: 989175016337

73. S. Thoms. "Nanofabrication handbook, Chapter 2: Electron beam lithography", CRC Press (2012), ISBN: 9781420090536.

74. K. Tomioka. "Selective-area growth of III-V nanowires and their applications", J. Mater. Res. 26, 2127 (2011).

75. X. Zhang, A.V. Whitney, J. Zhao, E.M. Hicks, and R.P. Van Duyne. "Advances in contemporary nanosphere lithographic techniques", $J$. Nanosci. Nanotechno. 6, 1 (2006).

76. S.-T. Lee, R. S. Kumar, S.-K. Jeon, M.-D. Kim, S.-G. Kim, and J.-E. Oh. "Influence of growth parameters on the optical properties of selective area grown GaN nanorods by plasma-assisted molecular beam epitaxy", $J$. Lumin. 151, 188 (2014).

77. H.A. Al-Khanbashia, and A M. Almarwani. "Evaluation of the optical properties of the InGaN/GaN quantum well nanopillar arrays prepared via MOVPE approach", Optik 164, 28 (2018).

78. S. Y. Chou. "Nanofabrication handbook, Chapter 9: Nanoimprint lithography", CRC Press (2012), ISBN: 9781420090536. 
79. X.J. Chen, J.S. Hwang, G. Perillat-Merceroz, S. Landis, B. Martin, D. Le Si Dang, J. Eymery, and C. Durand. "Wafer-scale selective area growth of GaN hexagonal prismatic nanostructures on c-sapphire substrate", $J$. Cryst. Growth 322, 15 (2011).

80. J.C. Brooksby, J. Mei, and F.A. Ponce. "Correlation of spectral luminescence with threading dislocations in green-light emitting InGaN quantum wells", Appl. Phys. Lett. 90, 231901 (2007).

81. S.A. Kukushkin, A.V. Osipov, V.N. Bessolov, B.K. Medvedev, V.K. Nevolin, and K.A. Tcarik. "Substrates for epitaxy of gallium nitride: new materials and techniques", Rev. Adv. Mater. Sci. 17, 1 (2008).

82. H. Amano. "Growth of GaN on sapphire via low-temperature deposited buffer layer and realization of p-type $\mathrm{GaN}$ by $\mathrm{Mg}$ doping followed by low-energy electron beam irradiation", Rev. Mod. Phys. 87, 1133 (2015).

83. E.V. Etzkorn, and D.R. Clarke. "Cracking of GaN films", J. Appl. Phys. 89, 1025 (2001).

84. V. Lebedev, J. Jinschek, U. Kaiser, B. Schröter, and W. Richter. "Epitaxial relationship in the AlN/Si(001) heterosystem", Appl. Phys. Lett. 76, 2029 (2000).

85. L. Liu, and J.H. Edgar. "Substrates for gallium nitride epitaxy", Mat. Sci. Eng. R 37, 61 (2002).

86. M.K. Sunkara, S. Sharma, R. Miranda, G. Lian, and E. C. Dickey. "Bulk synthesis of silicon nanowires using a low-temperature vapor-liquidsolid method", Appl. Phys. Lett. 79, 1546 (2001).

87. K.M. Lau, K. M. Wong, X. Zou, and P. Chen. "Performance improvement of GaN-based lightemitting diodes grown on patterned Si substrate transferred to copper", Optics Express 19, A956 (2011).

88. M.A. Herman, W. Richter, and H. Sitter. "Epitaxy: Physical principles and technical implementation, Chapter 15: Material-related problems of heteroepitaxy", Springer (2004), ISBN: 9783642087370.

89. G. Li, W. Wang, W. Yang, Y. Lin, H. Wang, Z. Lin, and S. Zhou. "GaNbased light-emitting diodes on various substrates: a critical review", Rep. Prog. Phys. 79, 056501 (2016).

90. S.-J. Tsaia, C.-L. Wub, N.-T. Tsaib, S.-S. Wong, and L.-W. Tu. "Epitaxy of obliquely aligned GaN nanorods on vertically oriented graphene nanosheets for transparent flexible piezoelectric nanogenerators", Carbon 130, 390 (2018). 
91. R.D. Dupuis. "Metalorganic chemical vapor deposition of III-V semiconductors", Science 226, 623 (1984).

92. M. Razeghi. "The MOCVD challenge. Vol.2: A survey of GaInAsP GaAs for photonic and electronic device applications", CRC Press (1995), ISBN: 9780750303095.

93. H. Morkoç. "III-Nitride semiconductor growth by MBE: Recent issues", J.Mater. Sci.-Mater. El. 12, 677 (2001).

94. K. Yasui. "Origin of "fast electrons" from slow atomic collisions", Phys. Rev. A 48, 1711 (1993).

95. W.D. Sproul, D.J. Christie, and D.C. Carter. "Control of reactive sputtering processes", Thin Solid Films 491, 1 (2005).

96. D. Depla. "Magnetrons, reactive gases and sputtering", (2013), ISBN: 9781304347817.

97. P.J. Kelly, and R.D. Arnell. "Magnetron sputtering: a review of recent development and applications", Vacuum 56, 159 (2000).

98. J.W. Shon, J. Ohta, K. Ueno, A. Kobayashi, and H. Fujioka. "Fabrication of full-color InGaN-based light-emitting diodes on amorphous substrates by pulsed sputtering", Sci. Rep. 4, 5325 (2014).

99. E. Nakamura, K. Ueno, J. Ohta, H. Fujioka, and M. Oshima. "Dramatic reduction in process temperature of InGaN-based light-emitting diodes by pulsed sputtering growth technique", Appl. Phys. Lett. 104, 051121 (2014).

100. M. Junaid. "Magnetron sputter epitaxy of GaN: Epilayers and nanorods", (2012), ISBN: 9789175197821.

101. T. Seppänen. "Growth and characterization of metastable wide band-gap $\mathrm{Al}_{1-\mathrm{x}} \mathrm{In}_{\mathrm{x}} \mathrm{N}$ epilayers”, (2006), ISBN: 9185523585.

102. L. Reimer. "Scanning electron microscopy: Physics of image formation and microanalysis", Springer (1998), ISBN 9783540389675. 


\section{Papers}

The papers associated with this thesis have been removed for copyright reasons. For more details about these see:

http://urn.kb.se/resolve?urn=urn:nbn:se:liu:diva-147647 